Journal of Thermal Engineering, Vol. 7, No. 1, pp. 271-290, January, 2021

Yildiz Technical University Press, Istanbul, Turkey

\title{
PERFORMANCE EVALUATION OF PARABOLIC TROUGH COLLECTOR WITH RECEIVER POSITION ERROR
}

\author{
Ramesh K. Donga ${ }^{1,{ }^{*}}$, Suresh Kumar ${ }^{2}$, Abhay Kumar $^{1}$
}

\begin{abstract}
In the present study, the effect of receiver position error on the optical and thermal performance of a parabolic trough collector (PTC) has been studied. Optical analysis of the PTC has been carried out by using Monte Carlo ray tracing (MCRT) method. The solar heat flux profile obtained from the optical analysis is coupled with the finite volume method (FVM) to study the thermal performance of the PTC. Simulations have been done for experimental SEGS LS2 solar collector used in Sandia National Laboratories. Syltherm 800 has been considered as heat transfer fluid (HTF). Receiver position errors in two directions i.e. along optical axis and lateral direction, have been taken. Results show that the receiver position error substantially influences the solar heat flux distribution and hence the temperature distribution on the absorber tube. The maximum circumferential temperature difference over the absorber tube increases up to by $199.7 \mathrm{~K}$ with receiver dislocation along the optical axis. The effects of the receiver position error on the optical efficiency and collector efficiency have also been studied. A maximum drop of $32 \%$ in the optical efficiency is observed when the receiver is displaced from the focus by $1.63 \%$ of focal length of the collector in both directions. The collector efficiency decreases by up to $14 \%$ when the receiver is offset by $1.63 \%$ of focal length of the collector along optical axis (away from the trough).
\end{abstract}

Keywords: Parabolic Trough Collector, Receiver Position Error, MCRT Method, Finite Volume Method, Concentrated Solar Power

\section{INTRODUCTION}

Solar energy is a clean unlimited free energy [1]. Recent developments in concentrated solar power (CSP) system have made solar energy the most promising [2]. In the concentrated solar power, mirrors concentrate a large number of sunrays on a small area to attain a high temperature [3]. Parabolic Trough Collector (PTC) is a proven industry scale solar power generation technology among all available CSP technologies [4]. The maximum extraction of thermal energy from available solar irradiation is a challenge for researchers. In the past few decades, many researchers [5-12] have presented studies to improve the efficiency of the PTC system; still, there is a scope for improvement in some aspects. PTC system comprises a reflective cylindrical parabola, which focuses the incident solar radiation on a receiver located on its focal line (Figure1). The receiver assembly consists of a metal absorber tube enclosed within a concentric glass tube but separated by a vacuum space. Absorber tube converts concentrated solar radiation into heat that is transferred to the heat transfer fluid (HTF) circulating through the solar field[13]. The outer surface of the absorber tube is coated with a material having high absorptivity and low emissivity to increase the absorption of solar radiation and to reduce the radiation heat loss from the absorber tube respectively [14, 15]. The evacuated space between the absorber tube and the glass tube minimizes the convective heat losses hence the total heat losses from the receiver to the atmosphere are reduced [14].

The thermal output of the PTC system depends on its optical efficiency and distribution of solar heat flux on the absorber tube. The optical efficiency and solar heat flux distribution of the PTC are significantly influenced by (i) the geometry of the collector (ii) sun incident angle (iii) optical properties of the materials used (iv) optical and

This paper was recommended for publication in revised form by Regional Editor Mohsen Sheikholeslami

${ }^{1}$ Mechanical Engineering Department, School of Engineering, University of Petroleum and Energy Studies, Dehradun-248007, India

${ }_{2}^{2}$ Mechanical Engineering Department, Tula's Institute, Dehradun248011, India

*E-mail address: rkdonga@ddn.upes.ac.in, rameshk.iitk@gmail.com,

Orcid id: 0000-0002-0306-1648, 0000-0003-1414-6206, 0000-0003-2630-083X

Manuscript Received 01 December 2018, Accepted 08 March 2019 
Journal of Thermal Engineering, Research Article, Vol. 7, No. 1, pp. 271-290, January, 2021

mechanical precision of the system elements [16-18]. In many cases, the optical performance of the PTC system is below the expectations even though the optical parameters such as reflectivity, specularity, transmissivity and absorptivity are within the design values. It may be due to optical and geometrical errors encountered during the construction and/or operation of the PTC system. The errors include receiver tube position error, profile error, local slope error, misalignment of the reflector and tracking error [18]. The identification of these errors and their effects on the thermal performance of the PTC system are important for its design.

Guven and Bannerot [18] studied different types of errors encountered and their influence on the optical performance of the PTC system. Thomas and Guven [19] proposed an analytical method to determine the effect of the receiver position error on circumferential distribution of heat flux on the outer surface of the absorber tube. A series of experimental and analytical studies have been carried out to study the effect of optical and geometrical errors on the optical performance of the PTC system [16, 20-27].

The receiver position error occurs due to (i) weight of the receiver assembly and weight of HTF causing sagging of the receiver assembly (ii) variation in specified shape of the receiver after welding and galvanization (iii) misalignment in the receiver support structure assembly and (iv) distortion of the collector supporting frame due to gravitational loading [17]. Due to these errors the receiver is not able to collect a large number of the reflected rays which leads to decreased performance of the PTC system. Very often, the receiver position error is approximated by an empirical probability distribution function. Still there is no existing correlation to statistically convert the actual receiver position error, present in the PTC geometry, to its corresponding error-probability distribution [17].

Treadwell [5] carried out a study on the influence of the receiver position error on the performance of the PTC. No significant change in performance of the PTC was observed when the receiver was displaced by $\pm 10 \%$ of its diameter from the focus in the lateral y-direction. He also suggested that receiver tube diameter can be increased in compensation of dislocation without a significant penalty on performance of the PTC [18]. Another studies carried out by Ratzel [7] and Ratzel and Sission [28] on the receiver dislocation also supported the observations of Treadwell [5]. Treadwell and Grandjean [29] stated that the receiver location error significantly degraded the annual performance of the PTC depending upon the magnitude of dislocation. Guven and Bannerot [18] studied the influence of the receiver mislocation on intercept factor. Zhu [17] and Binotti et al. [30] presented FirstOPTIC analytical technique to determine the influence of the receiver position error on the optical performance of the PTC system. Zhao et al. [27] reported that the receiver position error has significant effects on the solar flux distribution and optical performance of the collector. As evident from the above literature, the receiver position error significantly affects the optical efficiency of the PTC and circumferential distribution of solar flux on the absorber tube, hence the thermal performance of the receiver.

The circumferential distribution of solar heat flux on the outer surface of the absorber tube is required as it is one of the boundary conditions in thermal analysis of the PTC receiver. Jeter [31] presented a semi-finite formulation technique for calculating the solar flux distribution on the circumference of the PTC receiver. Later on, Jeter [32] presented an analytical technique to calculate the circumferential solar flux distribution. Khanna and Sharma [33] presented an explicit analytical expression for the calculation of solar flux distribution on an undeflected absorber tube, by considering the sun shape and optical errors. Another technique to obtain the solar heat flux distribution is ray tracing. Monte Carlo ray trace (MCRT) method is widely used, and it is a convenient technique to obtain the concentrated solar flux distribution [34, 35]. Cheng et al. [36], He et al. [37] and Cheng et al.[38] have estimated the distributed solar flux by MCRT method and the results of their studies were in good agreement with the analytical study of Jeter [31]. Ghomrassi et al. [4] used MCRT in SolTrace software to obtain the solar flux distribution for different absorber tube diameters. Mwesigye et al.[16] used MCRT method in SolTrace software to estimate the solar flux distribution on the absorber tube for different values of local slope error and mirror specular error. Zhao et al. [27] also obtain the solar flux distribution for different receiver position errors and tracking errors by using MCRT method.

Various heat transfer models are available to analyze the heat transfer in the receiver [16, 36, 39-42]. Cheng et al. [36] studied thermal performance of the receiver by coupling MCRT with FVM and compared their results with 
the experimental results of Dudley et al. [43]. It was concluded that the simulated results [36] were in close agreement with the experimental data [43], and the average relative error of collector efficiency was found within $\pm 2 \%$ [36]. Subsequently, many researchers [4, 16, 37, 38, 44-47] have used MCRT method coupled with FVM in their numerical studies for the thermal performance evaluation of the PTC system. A good agreement between the results of numerical studies [16,36-38] and experimental studies [43] has been reported.

Form the above discussions it is clear that the receiver position error occurs in the PTC due to various reasons and it significantly affects the heat flux distributions over the absorber tube. The variation in the heat flux distributions over the absorber tube may result an increase in temperature gradients in the absorber tube. The higher temperature gradients may result a damage of receiver due to thermal stress in the absorber tube. This study presents the effect of receiver position error on the temperature gradients in the absorber tube, optical efficiency and collector efficiency. Monte Carlo ray trace method is used to calculate the local heat flux distributions over the absorber tube. Later these heat flux distributions are used in the finite volume method to carry out the thermal analysis.

\section{PHYSICAL MODEL}

The schematic diagram of the parabolic trough collector is shown in Figure 1(a) and its cross sectional view in xy-plane with sunray path is shown in Figure 1(b). The PTC mainly consists of two components, a parabolic concentrator and a receiver. The other components such as metal support structure for concentrator, receiver supports and tracking mechanism are not shown as those are not relevant to the present study. As shown in Figure 1(b), the concentrator is a cylindrical parabola which reflects the incident solar rays on the central receiver. The curvature of the parabola follows the equation given as

Where ' $\mathrm{f}$ ' represents the focal length.

$$
y=x^{2} / 4 f
$$

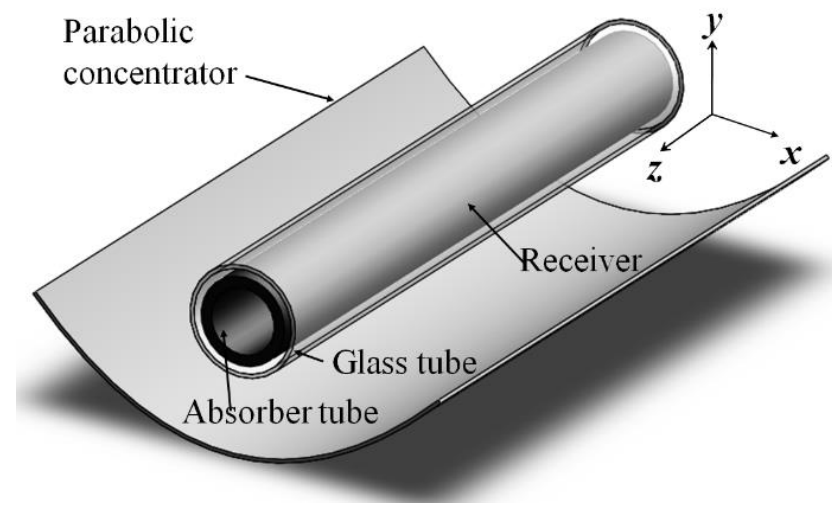

(a)

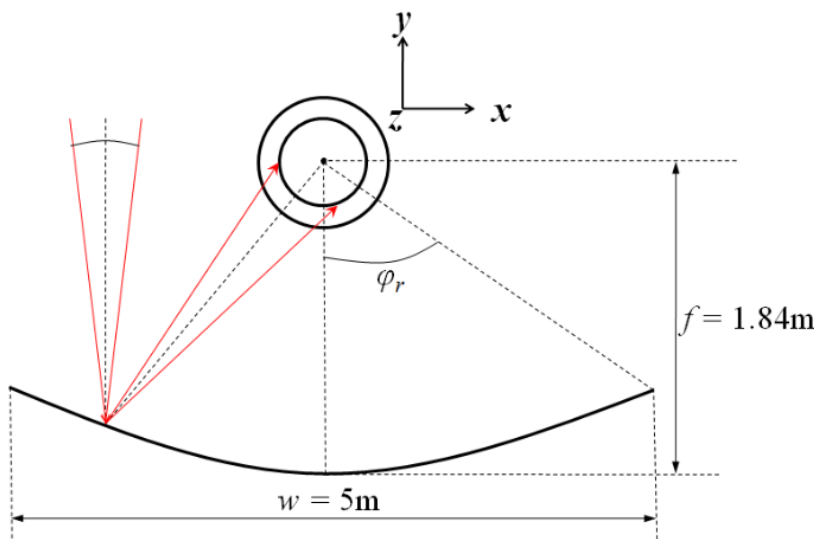

(b)

Figure 1. Schematic of the parabolic trough collector (a) Three-dimensional view (b) Cross-sectional view

The rim angle $\left(\varphi_{r}\right)$ is calculated by using equation :

$$
\varphi_{r}=\tan ^{-1}\left(\frac{w}{2\left(f-\frac{w^{2}}{16 f}\right)}\right)
$$

where ' $w$ ' represents the aperture width.

The central receiver collects the heat of concentrated solar radiation and transfers it to a heat transfer fluid flowing inside the absorber tube. The absorber tube is separated from the glass tube by an evacuated space as shown 
in Figure 2. The circumferential angle of the receiver is represented by ' $\theta$ '. The geometrical parameters of the present study are listed in Table 1.

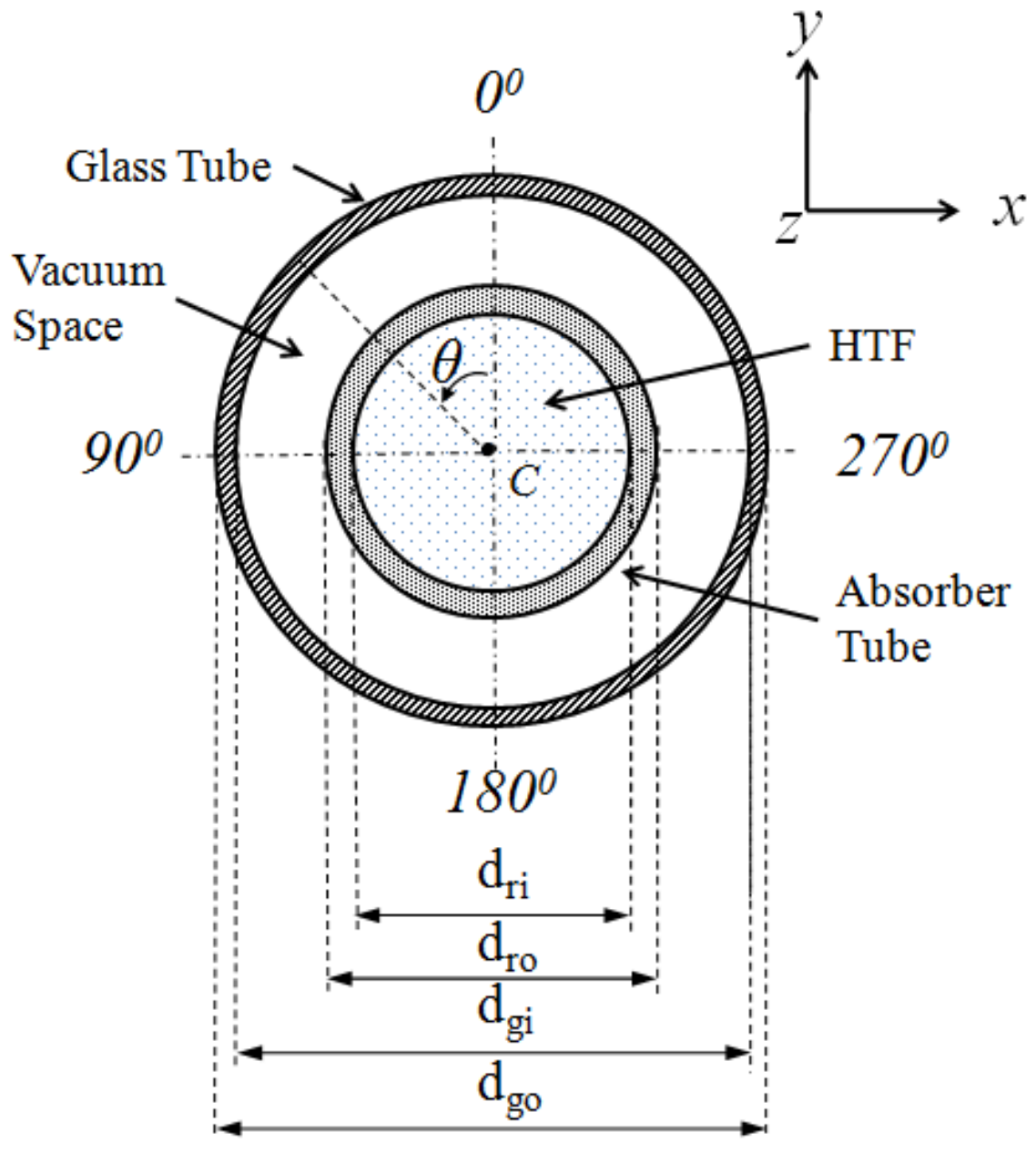

Figure 2. Cross-sectional view of receiver in xy-plane

Table 1. Geometrical parameter of PTC system used for simulation [43]

\begin{tabular}{|l|l|l|}
\hline Parameter & Symbol & Value \\
\hline Aperture width & $\mathrm{W}$ & $5 \mathrm{~m}$ \\
\hline Length of receiver & $L$ & $4 \mathrm{~m}$ \\
\hline Glass tube inner diameter & $d_{g i}$ & $0.109 \mathrm{~m}$ \\
\hline Glass tube outer diameter & $d_{g o}$ & $0.115 \mathrm{~m}$ \\
\hline Absorber tube inner diameter & $d_{r i}$ & $0.066 \mathrm{~m}$ \\
\hline Absorber tube outer diameter & $d_{r o}$ & $0.070 \mathrm{~m}$ \\
\hline Focal length & $F$ & $1.84 \mathrm{~m}$ \\
\hline
\end{tabular}

\section{MCRT RAY TRACING}

In the present study the distribution of the concentrated solar flux on the outer surface of the absorber tube has been obtained using Monte Carlo Ray Tracing method in SolTrace software. In SolTrace, the sun shape has been modeled as CSR0 measurement as suggested by Neumann et al. [49]. For simplifying the simulation, the profile error in parabolic curvature, mirror specularity error and local slope error of the parabolic concentrator are neglected. The 
optical properties of the mirror, glass tube and the absorber tube have been taken from the work of Dudley et al. [43] and are listed in Table 2. The slope and specularity errors associated with the glass tube and the absorber tube are not considered in the present work. To obtain an accurate heat flux profile, the number of ray interactions and the maximum number of generated sunrays have been set to $10^{6}$ and $10^{8}$ respectively. A direct normal irradiance (DNI) of $1000 \mathrm{~W} / \mathrm{m} 2$ is assumed for all the cases presented in this study [50]. Local concentration ratio (LCR) has been calculated by using equation given as

$$
L C R=q / D N I
$$

Where ' $\mathrm{q}$ ' is local heat flux in $\mathrm{Wm}^{-2}$, DNI is direct normal irradiation of sun in $\mathrm{Wm}^{-2}$

Table 2. Optical properties of the PTC system considered in the present study [38]

\begin{tabular}{|l|l|l|}
\hline Parameter & Symbol & Value \\
\hline Absorber tube absorptivity & $\alpha_{r}$ & 0.92 \\
\hline Absorber tube reflectivity & $\rho_{r}$ & 0.08 \\
\hline Glass tube transmissivity & $\tau_{g}$ & 0.935 \\
\hline Glass tube reflectivity & $\rho_{g}$ & 0.045 \\
\hline Mirror reflectivity & $\rho_{m}$ & 0.93 \\
\hline Mirror transmissivity & $\tau_{m}$ & 0 \\
\hline
\end{tabular}

Normalized receiver position errors in $x$-direction $\left(\sigma_{x}\right)$ and y-direction $\left(\sigma_{y}\right)$ are specified by equations given as

$$
\begin{gathered}
\sigma_{x}=\Delta x / f \\
\sigma_{y}=\Delta y / f
\end{gathered}
$$

' $\Delta \mathrm{x}$ ' and ' $\Delta \mathrm{y}$ ' are the receiver displacements in $\mathrm{x}$-direction and $\mathrm{y}$-direction from focus as shown in Figure 3. Range of $\sigma_{x}$ is considered from 0 to 0.0163 and for $\sigma_{y}$ it is considered from - 0.0163 to 0.0163 . As parabolic trough is symmetric about the y-axis, $\sigma_{x}$ in the negative direction is not considered.

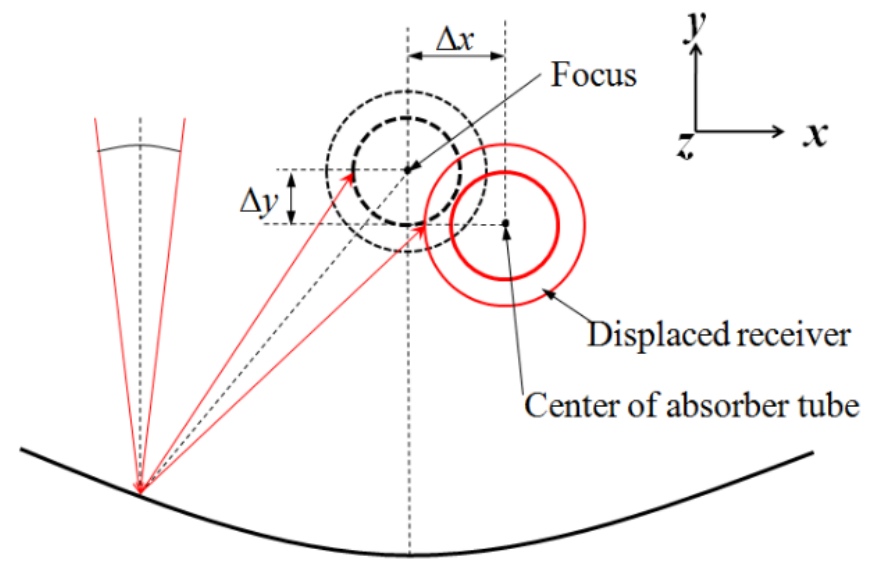

Figure 3. Illustration of receiver position error

The distribution of local concentration ratio (LCR) on the circumference of absorber tube of the parabolic trough concentrator has been obtained from SolTrace software by considering the optical and geometrical properties of components of the PTC system from the study of Jeter [31] and He et al. [37]. The results thus obtained are validated with the results of Jeter [31] and He et al. [37] as shown in Figure 4. 


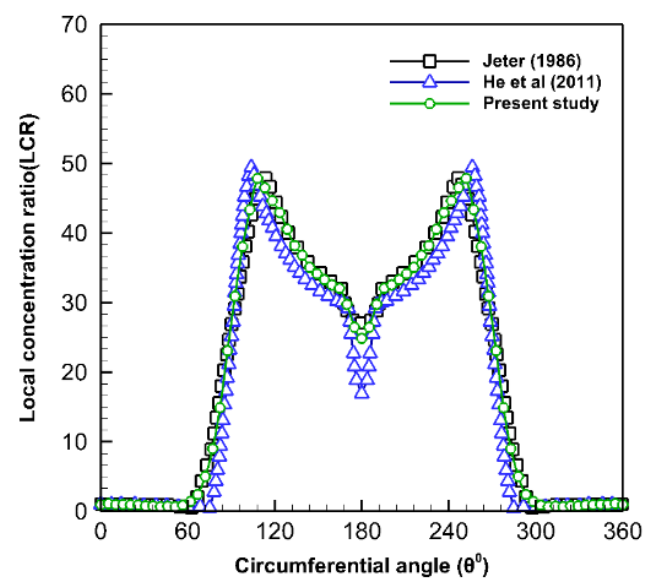

Figure 4. Comparison of present study with literature by local concentration ratio (LCR) for validation of SolTrace

\section{THERMAL ANALYSIS}

In the present study, the thermal analysis of the PTC has been carried out using the finite volume method (FVM) [51]. The value of distributed concentrated solar heat flux obtained by the MCRT method is introduced as a boundary condition for successive thermal analysis. The numerical simulations result in temperature distribution over the absorber and glass tube, heat loss from the receiver and heat gained by the HTF circulating in the absorber tube. The results of numerical simulations have been used for calculation of collector efficiency.

\section{Governing equations}

Reynolds-averaged Navier-Stokes (RANS) equations have been used to analyze the thermal performance of the receiver in FVM in the present study. Those are time averaged equations of turbulent flow for the conservation of mass, momentum, and energy given in Mwesigye et al. [16, 52]. Reynolds stresses have been calculated by using realizable eddy viscosity model. Two additional transport equations, turbulent kinetic energy (k) and turbulent dissipation rate ( ) are solved to find the turbulent kinetic energy and turbulent dissipation rate and hence eddy viscosity [53]. The evacuated space between the absorber tube and the glass tube has been modeled by using the discrete ordinates (DO) radiation model.

\section{Simulation assumptions and boundary conditions}

The following assumptions are made in the FVM analysis: (i) steady-state conditions (ii) all surfaces are gray and diffusive (iii) incompressible fluid (iv) heat transfer between the outer surface of absorber tube and inner surface of glass tube is by radiation only and (v) the physical properties of Syltherm 800 are polynomial function of temperature as already mentioned [38].

The boundary conditions are defined as follows:

(i) HTF inlet at absorber tube: inlet fluid velocity $=0.3$ to $0.3886 \mathrm{~ms}^{-1}$, temperature $\left(\mathrm{T}_{\text {in }}\right)=323$ to $573 \mathrm{~K}$.

(ii) HTF outlet at absorber tube: fully developed flow.

(iii) End surfaces of the absorber tube, glass tube and annular space (at $z=0$ and $z=4 m$ ): adiabatic walls.

(iv) outer surface of the absorber tube: circumferential heat flux distribution obtained from SolTrace is introduced by using user-defined function. Emissivity of the coated material on the outer surface of the absorber tube has been computed using Eq. (6) given by Dudley, Kolb [43] and Forristall [11].

$$
\varepsilon_{\text {ro }}=-0.065971+0.000327 T_{\text {ro }}
$$

(v) Inner surface of the absorber tube: no slip boundary condition.

(vi) Outer surface of the glass tube: convection and radiation boundary condition. Radiative heat transfer from the outer surface of the glass tube to the sky is calculated using Stefan-Boltzmann law. Sky is considered as a large enclosure and its effective temperature has been calculated by Eq. (7) $[4,16]$ 


$$
T_{\text {sky }}=0.0552 T_{a}^{1.5}
$$

Convective heat loss from the outer surface of the glass tube is calculated by specifying the heat transfer coefficient and ambient temperature. Heat transfer coefficient has been determined by using Eq. (8) given by Mullick and Nanda [54]

$$
h=V_{w}^{0.58} d_{g o}^{-0.42}
$$

The ambient temperature is taken as $298 \mathrm{~K}$ and wind velocity is taken as $2 \mathrm{~ms}^{-1}$ for all simulations in this study.

\section{Numerical simulations}

The governing equations specified in the section 4.1 have been solved using FVM with boundary conditions specified in section 4.2. Realizable k- $\varepsilon$ eddy viscosity model is used to model turbulent flow. Since this model cannot be applied near the solid wall, an enhanced wall treatment is employed near the wall regions. A structured mesh with hexahedral elements has been generated as shown in Figure 5. A very fine mesh has been generated near the wall to capture the velocity and temperature gradients. The non-dimensional distance $(\mathrm{y}+)$ near the wall has been maintained less than one for all simulations.

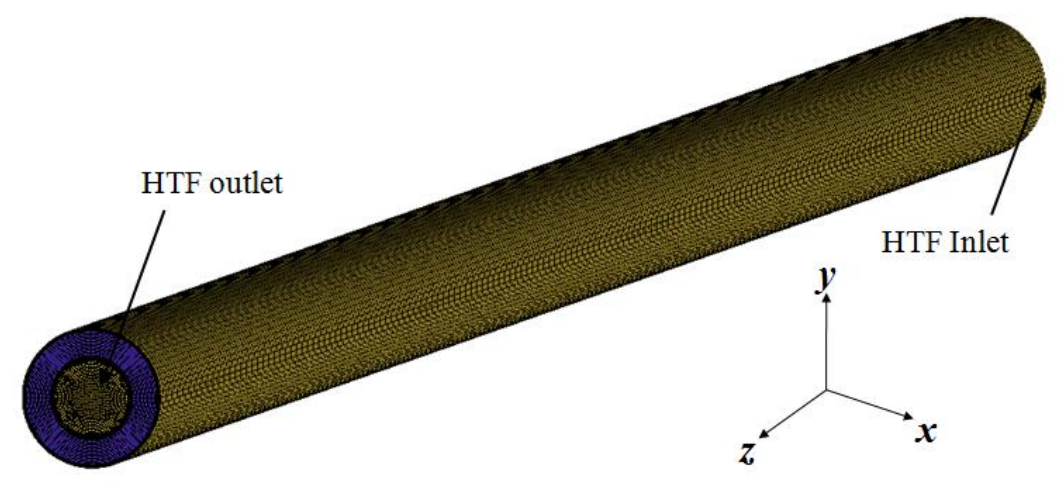

(a)

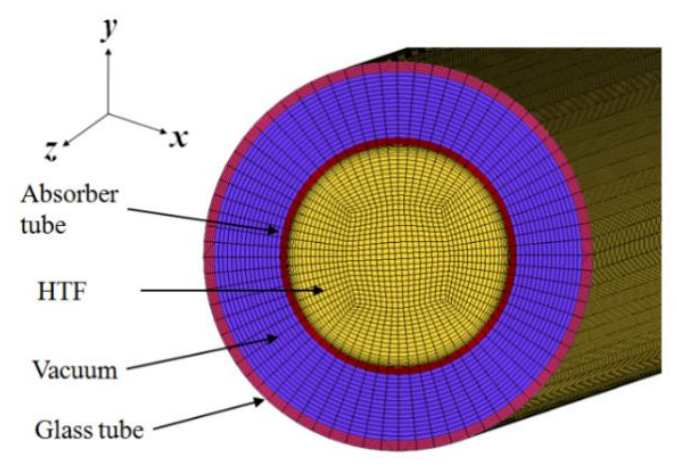

(b)

Figure 5. Mesh of the parabolic trough receiver

The generated mesh is used to perform the FVM analysis. Pressure based coupled algorithm is used to couple the velocity and the pressure fields. Since the momentum and pressure-based continuity equations are solved simultaneously in the coupled solver, solution converges in less time with higher stability than the segregated solver. A second order upwind scheme has been used for discretizing the momentum and energy equation, whereas pressure has been discretized using PRESTO scheme. Turbulent kinetic energy, turbulent dissipation rate and discrete ordinates 
equations are discretized using first-order upwind scheme. The convergence criteria for scaled residuals (mass, momentum, turbulent kinetic energy and turbulence dissipation rate) is taken less than 10-5, while the discrete ordinates residuals and energy residuals are taken less than 10-8 for all the simulations.

Simulations have been carried out for different mesh sizes to find the mesh independent solution and 857,472 elements have been found optimal. The numerical model has been validated by comparing the simulated results with the experimental data of Dudley et al. [43]. The simulated results are found to be in close agreement with experimental results as shown in Table 3.

Table 3. Mesh independent test

\begin{tabular}{|l|l|l|}
\hline Mesh size & \multicolumn{1}{|c|}{$\overline{\boldsymbol{f}}$} & \multicolumn{1}{c|}{} \\
\hline 655,586 & 0.02456923 & 47.21 \\
\hline 735,563 & 0.02480032 & 52.03 \\
\hline 802,324 & 0.02521953 & 53.13 \\
\hline 857,472 & 0.02545234 & 52.57 \\
\hline
\end{tabular}

The numerical model has been validated by comparing the simulated results with the experimental data of Dudley et al. [38]. The simulated results are found to be in close agreement with experimental results as shown in Table 4.

Table 4. Validation of present study with experimental data

\begin{tabular}{|c|c|c|c|c|c|c|c|c|}
\hline & $\begin{array}{c}\text { DNI } \\
\left(\mathrm{Wm}^{-2}\right)\end{array}$ & $\begin{array}{c}\text { Flow rate } \\
\left(\mathrm{L} \mathrm{min}^{-1}\right)\end{array}$ & $\begin{array}{c}\text { Wind } \\
\text { speed } \\
\left(\mathrm{ms}^{-1}\right)\end{array}$ & $\begin{array}{c}\text { Air } \\
\text { temperature } \\
\left({ }^{0} \mathrm{C}\right)\end{array}$ & $\begin{array}{c}\mathrm{T}_{\text {in }} \\
\left({ }^{\circ} \mathrm{C}\right)\end{array}$ & $\begin{array}{c}\mathrm{T}_{\text {out }}\left({ }^{0} \mathrm{C}\right) \\
(\text { Experimental })\end{array}$ & $\begin{array}{c}\mathrm{T}_{\text {out }}\left({ }^{0} \mathrm{C}\right) \\
(\text { Present study) }\end{array}$ & $\begin{array}{c}\% \\
\text { error }\end{array}$ \\
\hline 1 & 933.7 & 47.7 & 2.6 & 21.2 & 102.2 & 124 & 128.08 & 3.29 \\
\hline 2 & 937.9 & 55.5 & 1 & 28.8 & 297.8 & 316.9 & 318.22 & 0.41 \\
\hline 3 & 920.9 & 56.8 & 2.6 & 29.5 & 379.5 & 398 & 398.64 & 0.16 \\
\hline 4 & 880.6 & 55.6 & 2.9 & 27.5 & 299 & 317.2 & 318.02 & 0.82 \\
\hline 5 & 909.5 & 54.7 & 3.3 & 26.2 & 250.7 & 269.4 & 270.8 & 0.51 \\
\hline 6 & 968.2 & 47.8 & 3.7 & 22.4 & 151 & 173.3 & 175.6 & 1.32 \\
\hline 7 & 982.3 & 49.1 & 2.5 & 24.3 & 197.5 & 219.5 & 221.75 & 1.02 \\
\hline
\end{tabular}

\section{RESULTS AND DISCUSSION}

The effects of the receiver position error on circumferential heat flux distribution over the absorber tube and thermal performance of the PTC have been studied. The results have been discussed in subsequent sections.

\section{Circumferential distribution of heat flux on the absorber tube}

The ideal position of the receiver is taken as $\sigma_{x}=0$ and $\sigma_{y}=0$ i.e. the receiver is concentric with the focus of the parabolic trough. Figure 6 shows the circumferential distribution of heat flux on the outer surface of the absorber tube for $\sigma_{x}=0.0054$ and $\sigma_{y}=-0.0054$. The circumferential heat flux distribution has been divided into two major regions ' $\mathrm{A}$ ' and ' $\mathrm{B}$ ' for discussing the pattern of heat flux distribution on the absorber tube as shown in Figure 6. Further, the regions ' $\mathrm{A}$ ' and ' $\mathrm{B}$ ' are divided into sub-regions namely shadow effect region represented by $\mathrm{A}_{1}$ and $\mathrm{B}_{1}$, increasing solar flux area represented by $\mathrm{A}_{2}$ and $\mathrm{B}_{2}$, reducing solar flux area represented by $\mathrm{A}_{3}$ and $\mathrm{B}_{3}$ and the direct radiation area represented by $\mathrm{A}_{4}$ and $\mathrm{B}_{4}$. The peak flux in region $\mathrm{A}$ is termed as $q_{P A}$, the peak flux in the region $\mathrm{B}$ is termed as $q_{P B}$ and minimum heat flux in shadow effect area is termed as $q_{C}$. The regions ' $\mathrm{A}$ ' and 'B' are separated at the location of $q_{C}$ on the circumference of the absorber tube. 
Journal of Thermal Engineering, Research Article, Vol. 7, No. 1, pp. 271-290, January, 2021

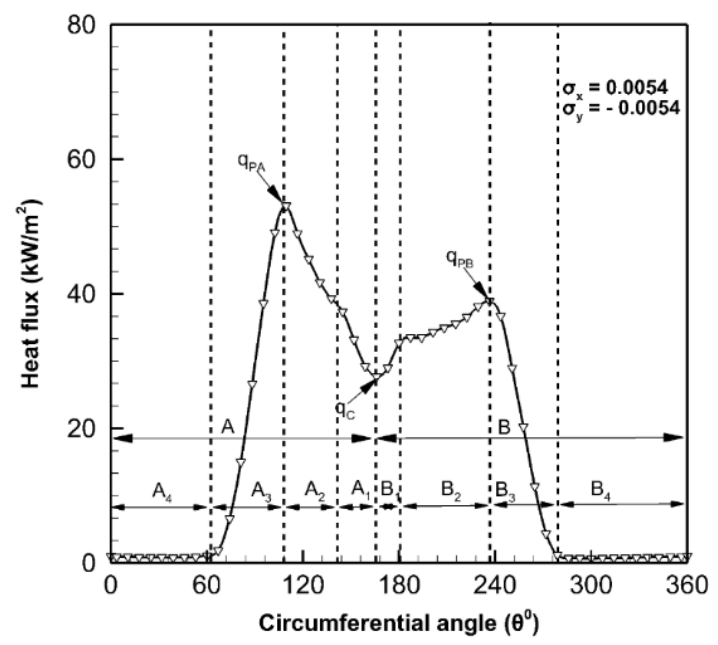

Figure 6. Heat flux distribution on the circumference of absorber tube

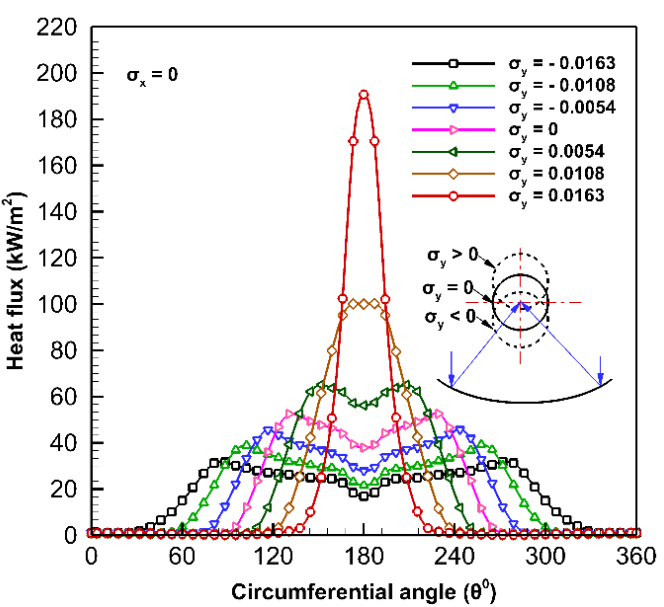

(a) $\sigma_{x}=0$

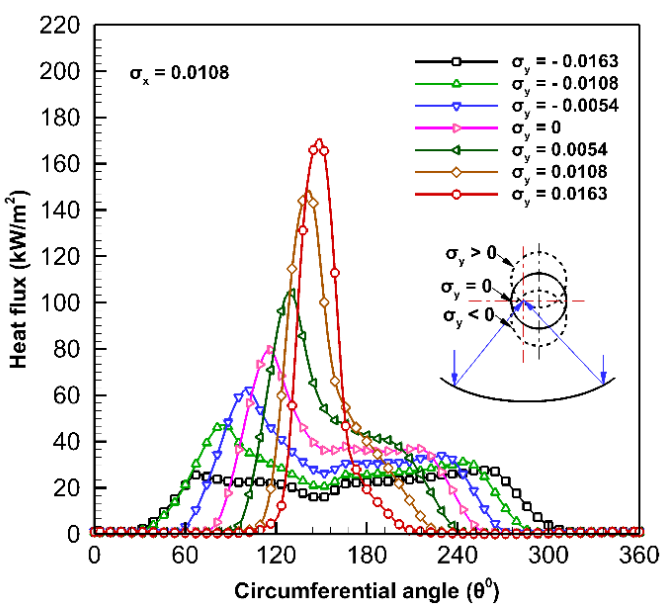

(c) $\sigma_{x}=0.0108$

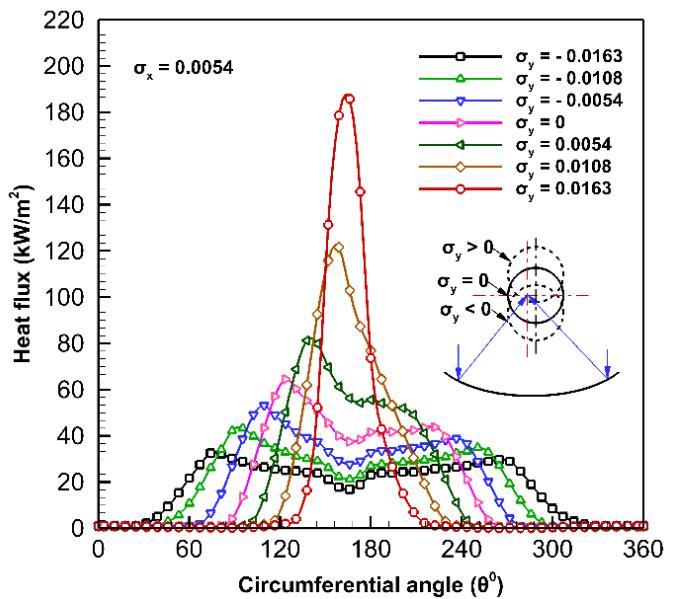

(b) $\sigma_{x}=0.0054$

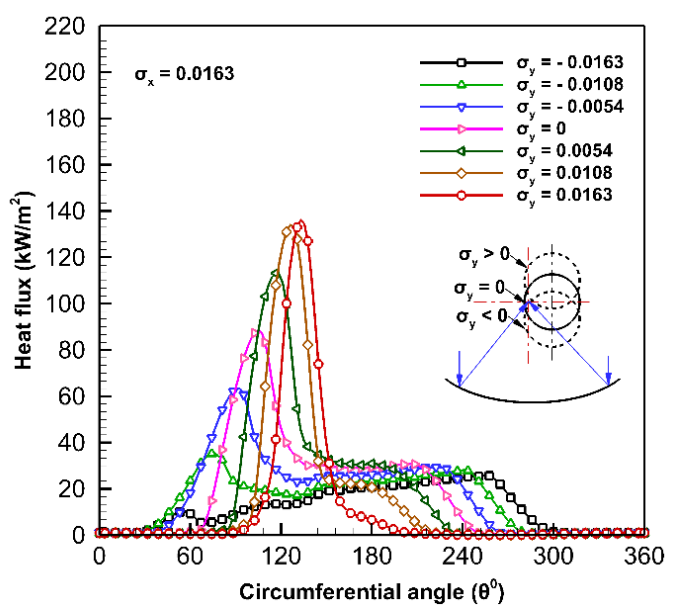

(d) $\sigma_{x}=0.0163$

Figure 7. Heat flux distribution on the circumference of absorber tube for receiver position errors $\sigma_{y}=-0.0163$ to 0.0163 and (a) $\sigma_{x}=0$ (b) $\sigma_{x}=0.0054$ (c) $\sigma_{x}=0.0108$ (d) $\sigma_{x}=0.0163$ 
Journal of Thermal Engineering, Research Article, Vol. 7, No. 1, pp. 271-290, January, 2021

Figure 7(a)-(d) show the effect of the receiver position error on the distribution of heat flux over the circumference of the absorber tube. The distribution of heat flux on the circumference of the absorber tube with respect to the circumferential angle $\theta$ is shown in Figure 7(a) for $\sigma_{x}=0$ and for a range of $\sigma_{y}=-0.0163$ to 0.0163 . It can be observed that the distributed heat flux is symmetric about $\theta=180^{\circ}$. The values of peak fluxes $q_{P A}$ and $q_{P B}$ are equal and increase when the receiver is displaced from $\sigma_{y}=0$, in positive y-direction i.e. away from the trough and decrease when the receiver is offset in negative y-direction (towards the trough). As $\sigma_{y}$ changes from - 0.0163 to 0.0163 , the angle spans of region $\mathrm{A}_{4}$ and $\mathrm{B}_{4}$ increase whereas the angle spans of $\mathrm{A}_{3}$ and $\mathrm{B}_{3}$ decrease. The angle span refers to the sector of the circular cross-section of the absorber tube. The angle span $\left(A_{1}+B_{1}+A_{2}+B_{2}\right)$ between two peak fluxes decreases when the absorber tube is displaced in the y-direction from $\sigma_{y}=-0.0163$ to 0.0108 . The angle span is zero between two peaks at $\sigma_{y}=0.0108$ and for higher values of $\sigma_{y}$ only one peak is obtained. Thus, it can be said that due to the displacement of the receiver, from the focus, away from the trough, concentrated rays fall on a smaller circumferential portion of the absorber tube and a bigger circumferential portion is exposed to the direct sun radiation. Therefore, the peak flux increases as observed in Figure 7(a) and vice versa occurs when the receiver is displaced, from the focus, towards the trough. Figure 7(b) shows the distribution of heat flux for $\sigma_{x}=0.0054$ and for a range of $\sigma_{y}=-0.0163$ to 0.0163 . It can be seen that the distribution of heat flux is not symmetric. The region 'A' contracts and region 'B' expands with peaks $q_{P A}$ and $q_{P B}$ skewed towards left with respect to the ideal position of the receiver. The value of $q_{P A}$ is higher than the value of $q_{P B}$ for whole range of $\sigma_{y}$, however, both the heat fluxes increase as $\sigma_{y}$ changes from - 0.0163 to 0.0163 . The difference between the values of $q_{P A}$ and $q_{P B}$ is very small when $\sigma_{y}$ is equal to -0.0163 and it drastically increases until $\sigma_{y}$ attains a value of 0.0054 and for higher values of $\sigma_{y}$ only one peak is obtained. The shift of peak flux towards left with respect to the ideal position of the receiver occurs due to increase in the concentration of falling rays on the lower left portion of the absorber tube because of the receiver displacement in positive x-direction $\left(\sigma_{x}>0\right)$. Figure 7(c) shows the distribution of heat flux for $\sigma_{x}=0.0108$ and a range of $\sigma_{y}=$ 0.0163 to 0.0163 . It is observed that there is more shift in heat flux peaks in comparison to Figure 7 (b). The value of $q_{P A}$ is lower than the value of $q_{P B}$ for $\sigma_{y}=-0.0163$, whereas the value of $q_{P A}$ is higher than the value of $q_{P B}$ for a range of $\sigma_{y=-} 0.0108$ to 0 , and only one peak exists for $\sigma_{y}>0$. Figure 7(d) shows the distribution of heat flux for $\sigma_{x}=$ 0.0163 and for a range of $\sigma_{y}=-0.0163$ to 0.0163 . A similar trend of heat flux distribution is observed in Figure 7(d). However, there is a slight decrease in the values of peak fluxes with an increase in the skewness of peaks more towards the left with respect to the ideal position. From the observations of Figure 7(a)-(d), it is found that for a range of $\sigma_{y}=$ - 0.0108 to 0.0054 , the value of $q_{P A}$ increases and is skewed with increasing in receiver position error in x-direction, for a range of $\sigma_{x}=0$ to 0.0163 , because the same amount of rays reaches on the reduced area on the lower left portion of the absorber tube. However, the value of $q_{P A}$ decreases at $\sigma_{y}$ equal to -0.0163 and 0.0163 when $\sigma_{x}$ increases in the range 0 to 0.0163 .

\section{Optical efficiency of PTC}

The optical efficiency which is defined as the ratio of the energy absorbed by the absorber tube to the solar radiation incident on the aperture area has been estimated using the Eq. (9) given below

$$
\eta_{o}=\frac{Q_{c}+Q_{\text {lost }}}{I . W \cdot L}
$$

Heat gained by the HTF is calculated using Eq. (10)

$$
Q_{c}=\dot{m}\left(\overline{T_{\text {out }} C_{p, \text { out }}}-\overline{T_{\text {ln }} C_{p, \text { ln }}}\right)
$$




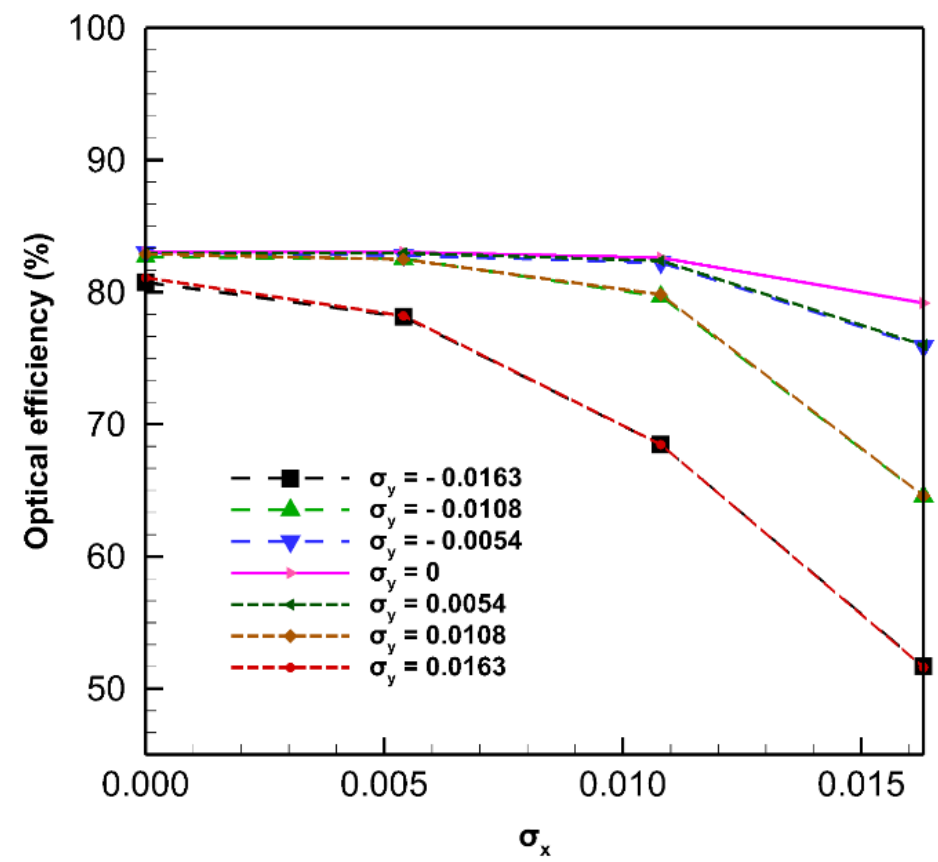

Figure 8. Optical efficiency for $\sigma_{x}=0$ to 0.0163 and $\sigma_{y}=-0.0163$ to 0.0163

The values of the optical efficiency of the PTC for a range of $\sigma_{x}=0$ to 0.0163 and for a range of $\sigma_{y}=-0.0163$ to 0.0163 are shown in Figure 8. For all the receiver positions in the x-direction ( $\sigma_{x}=0$ to 0.0163 ), the optical efficiency is almost the same when the receiver is offset by the same amount in the positive or negative y-direction. It is observed from Figure 7(a) to (d) that, at $\sigma_{y}=-0.0163$, the magnitude of peak flux is low but the concentrated heat flux is distributed over a wider surface area of the absorber tube in comparison to the heat flux distribution at $\sigma_{y}=0.0163$ where the case is reversed. Since the areas under the heat flux curves are equal (for $\sigma_{y}=-0.0163$ and 0.0163 ) same optical efficiency is obtained when the receiver is displaced equally either in the positive or negative y-direction. Similar observation is also found for the pair $\sigma_{y}=-0.0108,0.0108$ and $\sigma_{y}=-0.0054,0.0054$ as shown in Figure 8. It is also observed that the values of the optical efficiency of the collector are similar for the same amount of displacement of the receiver in the lateral y-direction for different values of $\sigma_{x}$, therefore $\pm \sigma_{y}$ notation is used for discussion. It has been observed that at $\sigma_{y}=0$ there is no variation in the optical efficiency, when $\sigma_{x}$ changes from 0 to 0.0108 , thereafter efficiency slightly decreases. In addition, no significant variation in the efficiency is observed for $\sigma_{y}= \pm 0.0054$ when $\sigma_{x}$ changes from 0 to 0.0108 after that, the efficiency decreases till $\sigma_{x}$ changes to 0.0163 . In comparison to $\sigma_{y}= \pm$ 0.0054 , no significant drop in efficiency is observed at $\sigma_{y}= \pm 0.0108$ and for range of $\sigma_{x}$ from 0 to 0.0054 . A continuous fall in the efficiency is observed at $\sigma_{y}= \pm 0.0163$ as the $\sigma_{x}$ varies from 0 to 0.0163 .

\section{Receiver thermal performance}

Figure 9 shows the velocity profile of HTF in the yz-plane passing through the centerline of the receiver at z-locations equal to $0.5,1,1.5,2,2.5$ and $3 \mathrm{~m}$. It can be observed that a fully developed flow is obtained after $2 \mathrm{~m}$ from the inlet of the absorber tube, which satisfies the condition of fully developed flow. Figure 10 shows the circumferential distribution of the temperature on the outer surface of the absorber tube at $\mathrm{z}=1,2,3$ and $4 \mathrm{~m}$ for inlet fluid temperature equal to $373 \mathrm{~K}$. As shown in Figure 10, the variation in temperature distribution is negligible in zdirection in comparison to the variation in temperature in $\theta$-direction due to non-uniform circumferential heat flux distribution. Therefore, only the temperature distribution in $\theta$-direction at $\mathrm{z}=4 \mathrm{~m}$ is discussed for different receiver position errors ( $\sigma_{x}$ and $\sigma_{y}$ ). 


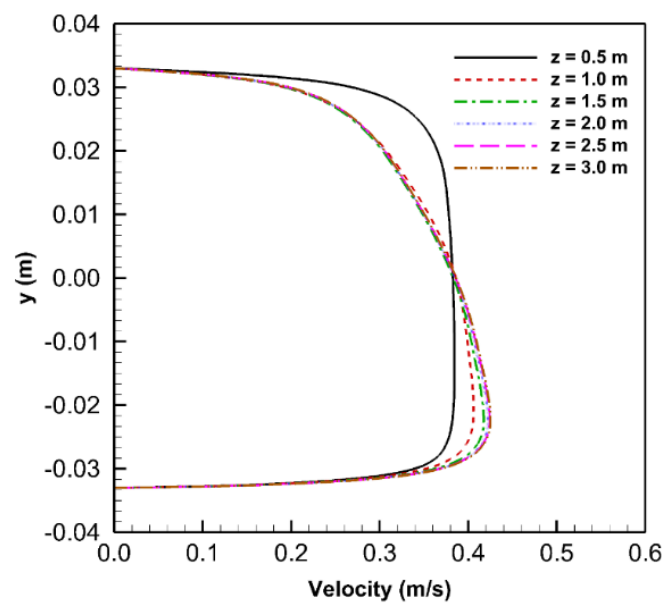

Figure 9. Velocity profiles at different z locations for receiver position errors $\sigma_{x}=\sigma_{y}=0$

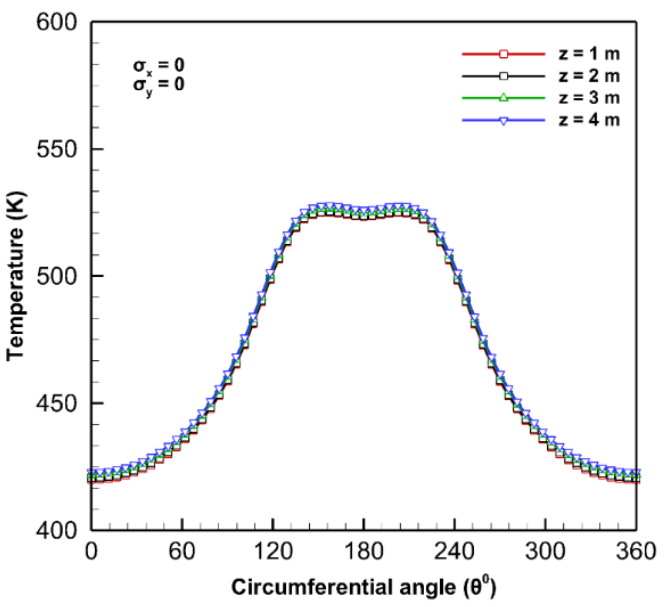

Figure 10. Circumferential distribution of temperature on absorber tube at $\mathrm{z}=1,2,3$ and $4 \mathrm{~m}$

\section{Streamlines and temperature contours}

The spatial distribution of the temperature and streamlines at the outlet of the absorber tube $(\mathrm{z}=4 \mathrm{~m})$ are shown in Figure 11(a) - (t) for five receiver position errors in y-direction $\left(\sigma_{y}=-0.0163,-0.0108,0,0.0108\right.$ and $0.0163)$ and for four receiver position errors in $\mathrm{x}$-direction $\left(\sigma_{x}=0,0.0054,0.0108\right.$ and 0.0163$)$. It has been observed that in Figure 11(a) - (t), the value of the temperature in the lower portion of the absorber tube (facing the trough) is higher than that of in the upper portion (exposed to direct sun radiation) due to variation in concentrated heat flux. Because of this reason the HTF flowing over the lower surface of the absorber tube experiences differential heating. The increase in the temperature of the HTF decreases its density causing it to move upwards along the sidewall of the absorber tube due to buoyance forces (see the pattern of streamlines in Fig 11). At the upper region of the absorber tube, the streamlines along the sidewall of the absorber tube interact with each other in opposite direction, thus enhancing the mixing of fluid. Since, the HTF at the bottom of the absorber tube moves upward along the sidewall of absorber tube, the colder fluid from the central region rush to fill it. This cyclic movement of the fluid creates two counter rotating vortices in the xy-plane. Therefore, any change in the distribution of heat flux over the absorber tube changes the orientation of streamlines and thus the shape and inclination of counter rotating vortices. The ideal position of the receiver $\left(\sigma_{x}=\sigma_{y}=0\right)$ is shown in Figure 11(c). When $\sigma_{x}=0$, for whole range of $\sigma_{y}$ the vortex streamlines and temperature distributions are symmetrical as seen in Figure 11(a) - (e) due to symmetric heat flux distribution. When 
$\sigma_{x}$ increases to 0.0054 in Figure 11(f) - (j) for all values of $\sigma_{y}$, the streamlines are asymmetric due to skewness of the heat flux distributions and higher value of $q_{P A}$ compared to $q_{P B}$ as observed in Figure 7(b). Because of this, the left vortex moves upward and right vortex moves downward. The upward and downward movement of vortices is directly correlated to the difference between $q_{P A}$ and $q_{P B}$ and skewness of flux distributions. Similar trends are also observed in Figure 11(k) - (o) for $\sigma_{x}=0.0108$ and Figure 11(p) - (t) for $\sigma_{x}=0.0163$ due to the skewness of flux distribution and differences between the $q_{P A}$ and $q_{P B}$ as observed in Figure 7(c) and (d) respectively.

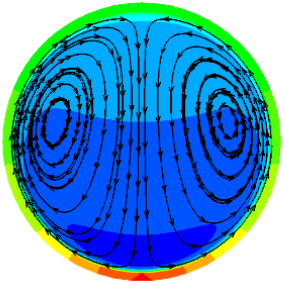

(a) $\sigma_{x}=0, \sigma_{y}=0.0163$

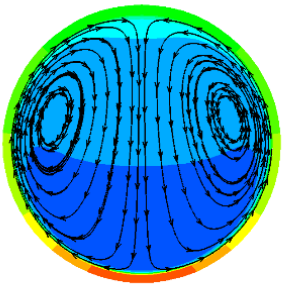

(b) $\sigma_{x}=0, \sigma_{y}=0.0108$

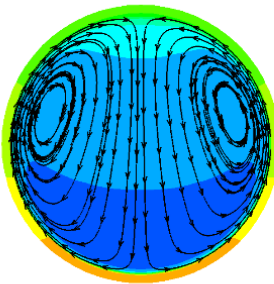

(c) $\sigma_{x}=0, \sigma_{y}=0$

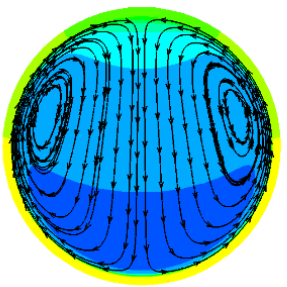

(d) $\sigma_{x}=0, \sigma_{y}=-0.0108$

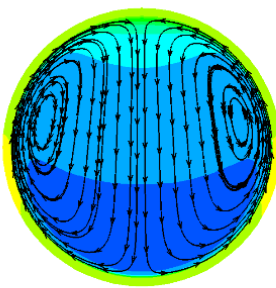

(e) $\sigma_{x}=0, \sigma_{y}=-0.0163$

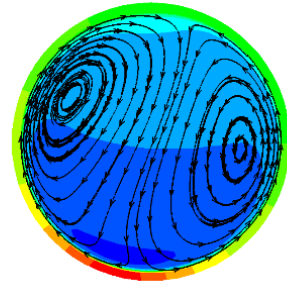

(f) $\sigma_{x}=0.0054, \sigma_{y}=0.0163$

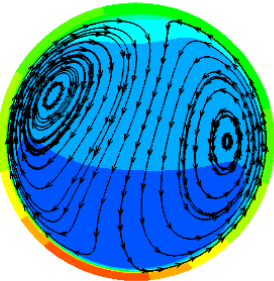

(g) $\sigma_{x}=0.0054, \sigma_{y}=0.0108$

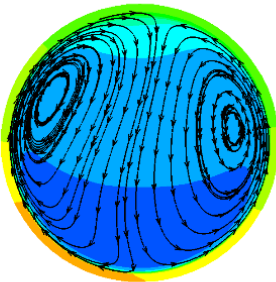

(h) $\sigma_{x}=0.0054, \sigma_{y}=0$

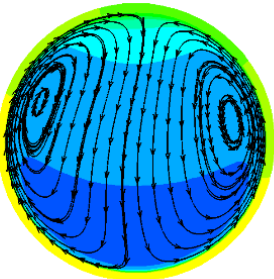

(i) $\sigma_{x}=0.0054, \sigma_{y}=-0.0108$

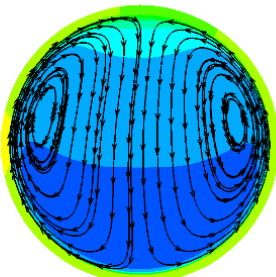

(j) $\sigma_{x}=0.0054, \sigma_{y}=-0.0163$

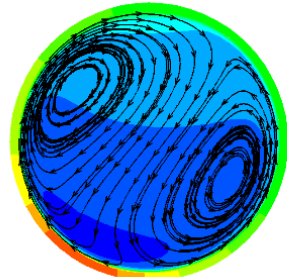

(k) $\sigma_{x}=0.0108, \sigma_{y}=0.0163$

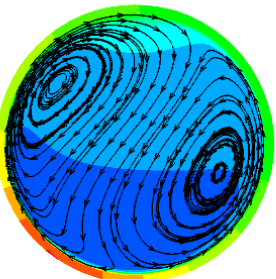

(I) $\sigma_{x}=0.0108, \sigma_{y}=0.0108$

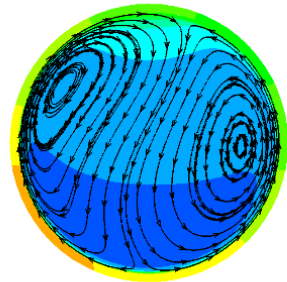

(m) $\sigma_{x}=0.0108, \sigma_{y}=0$

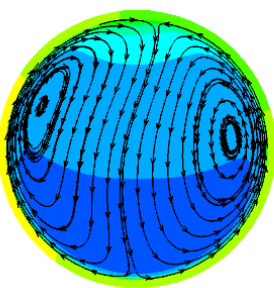

(n) $\sigma_{x}=0.0108, \sigma_{y}=-0.0108$

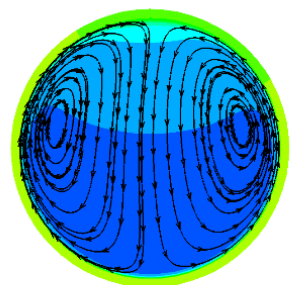

(o) $\sigma_{x}=0.0108, \sigma_{y}=-0.0163$

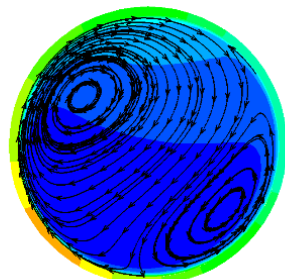

(p) $\sigma_{x}=0.0163, \sigma_{y}=0.0163$

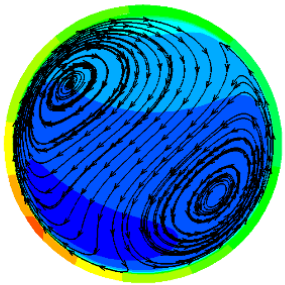

(q) $\sigma_{x}=0.0163, \sigma_{y}=0.0108$

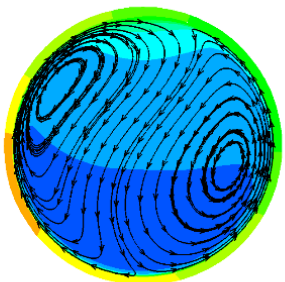

(r) $\sigma_{x}=0.0163, \sigma_{y}=0$

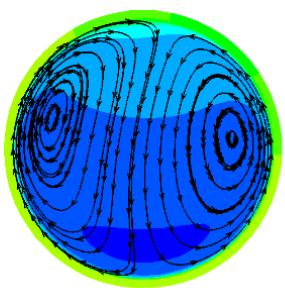

(s) $\sigma_{x}=0.0163, \sigma_{y}=-0.0108$

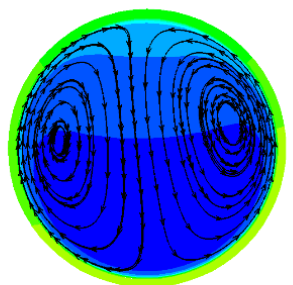

(t) $\sigma_{x}=0.0163, \sigma_{y}=-0.0163$

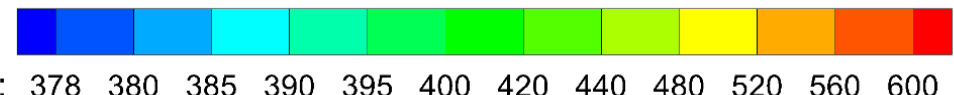

Temperature: $\begin{array}{llllllllllll}378 & 380 & 385 & 390 & 395 & 400 & 420 & 440 & 480 & 520 & 560 & 600\end{array}$

Figure 11. Temperature contours and streamlines at the outlet of absorber tube 


\section{Circumferential distribution of temperature on absorber tube}

The effect of the receiver position error on the circumferential distribution of temperature on the outer surface of the absorber tube at $\mathrm{z}=4 \mathrm{~m}$, for inlet fluid temperature of $373 \mathrm{~K}$, is shown in Figure 12(a) - (d). The temperature distribution follows similar trends of heat flux distribution, but the curves of the former one are flatter than those of the latter one. Figure 12(a) shows the temperature profile on the absorber tube for $\sigma_{x}=0$ and for a range of $\sigma_{y}=$ 0.0163 to 0.0163 . It can be seen that the maximum temperature $\left(\mathrm{T}_{\max }\right)$ and the difference between the maximum and minimum temperature on the absorber tube $(\Delta \mathrm{T})$ increase when the receiver is offset in positive $\mathrm{y}$-direction from the focus i.e. away from the trough. These decrease when receiver is displaced in negative y-direction from the focus of the parabolic trough. When the receiver is at ideal position, the computed values of $\mathrm{T}_{\max }$ and $\Delta \mathrm{T}$ at the outlet are found to be $527.7 \mathrm{~K}$ and $104.8 \mathrm{~K}$ respectively. When the value of $\sigma_{y}$ is equal to -0.0163 , the $\mathrm{T}_{\max }$ and $\Delta \mathrm{T}$ are found to be $482.7 \mathrm{~K}$ and $42 \mathrm{~K}$ respectively. At $\sigma_{y}$ equal to $0.0163, \mathrm{~T}_{\max }$ and $\Delta \mathrm{T}$ are found to be $606.4 \mathrm{~K}$ and $199.7 \mathrm{~K}$ respectively. So the positive y-direction errors (displacement of the receiver away from the trough) should be avoided to protect the receiver from overheating and thermal stresses. Figure 12(b), (c) and (d) shows the temperature profile on absorber tube for $\sigma_{x}=0.0054, \sigma_{x}=0.0108$ and $\sigma_{x}=0.0168$ respectively. As shown in Figs 12 (b) - (d) the temperature profile is asymmetric and follows the similar trends of the heat flux but the temperature in the right side is slightly lower than the left side. That is mainly because of convective currents caused by asymmetric heat flux distribution as shown in Figure 11.

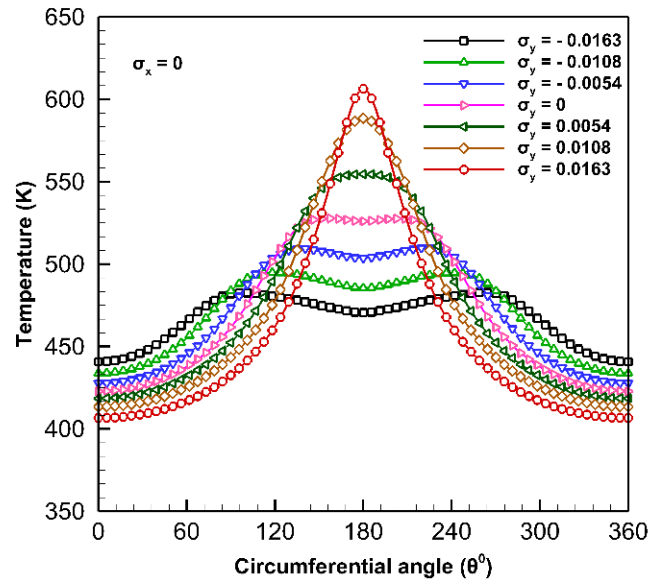

(a) $\sigma_{x}=0$

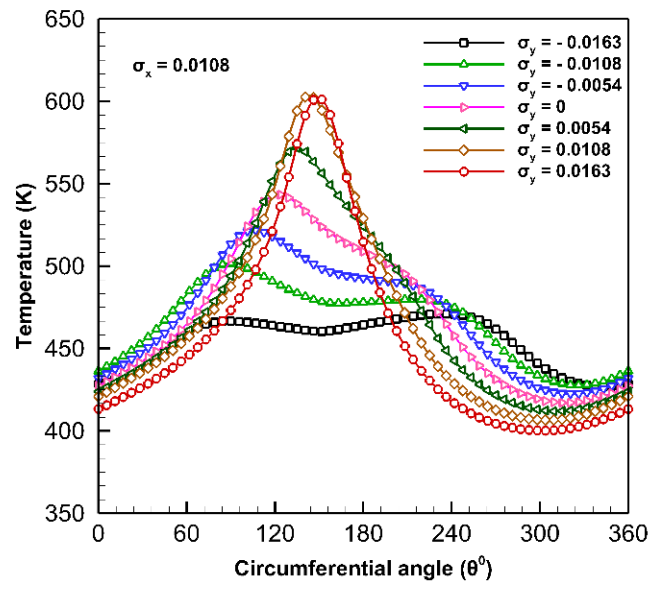

(c) $\sigma_{x}=0.0108$

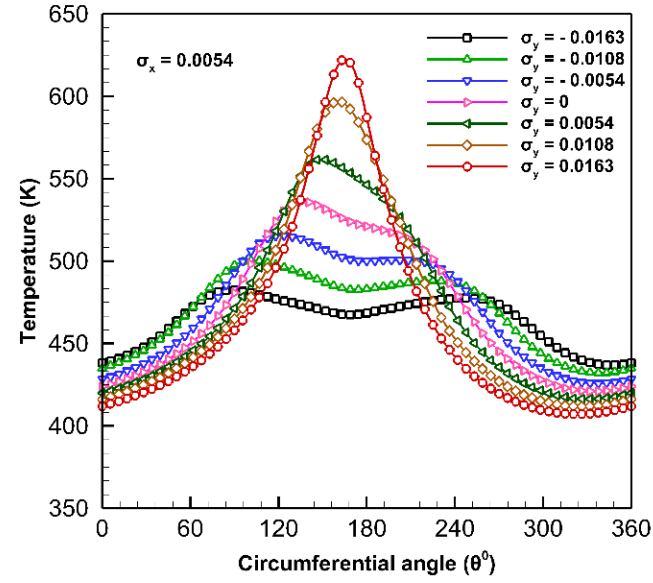

(b) $\sigma_{x}=0.0054$

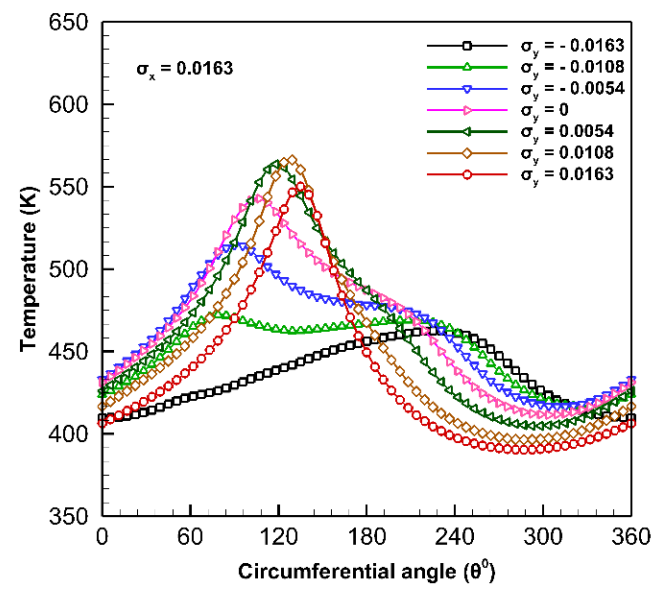

(d) $\sigma_{x}=0.0163$

Figure 12. Circumferential distribution of temperature on outer surface of the absorber tube at $\mathrm{z}=4 \mathrm{~m}$ for inlet temperature $373 \mathrm{~K}, \sigma_{y}=-0.0163$ to 0.0163 and (a) $\sigma_{x}=0$ (b) $\sigma_{x}=0.0054$ (c) $\sigma_{x}=0.0108$ (d) $\sigma_{x}=0.0163$ 


\section{Collector efficiency}

The collector efficiency is calculated as the ratio of heat gained by the HTF to the solar radiation incident on the aperture area given in Eq. (11)

$$
\eta_{c}=\frac{Q_{c}}{I \cdot W \cdot L}
$$

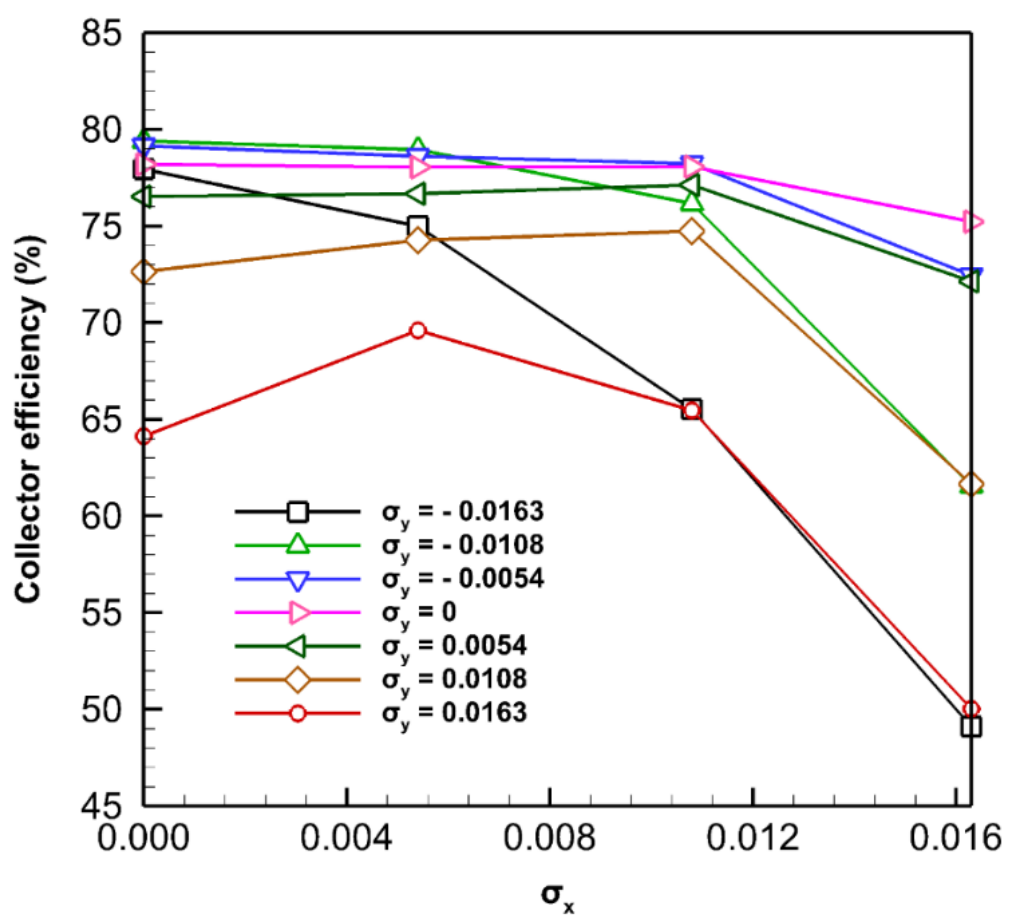

Figure 13. Collector efficiency for $\sigma_{x}=0$ to 0.0163 and $\sigma_{y}=-0.0163$ to 0.0163

The effect of the receiver position error on the collector efficiency is shown in Figure 13. The parameters considered for calculating the collector efficiency are: inlet fluid temperature $=373 \mathrm{~K}$, range of receiver position error for $\sigma_{x}=0$ to 0.0163 and for $\sigma_{y}=-0.0163$ to 0.0163 . It has been observed that the efficiency may increase with increase or decrease in the receiver position error. For ideal position of the receiver $\left(\sigma_{y}=0\right.$ and $\left.\sigma_{x}=0\right)$, the computed value of collector efficiency is $78.1 \%$. Whereas when $\sigma_{x}$ increases to 0.0163 keeping $\sigma_{y}$ equal to zero, a $3 \%$ fall in collector efficiency is observed. However, when $\sigma_{y}$ increases from 0 to 0.0163 keeping $\sigma_{x}$ equal to zero, a $14 \%$ fall in the collector efficiency is observed due to increase in non-uniformity of heat flux. In other condition when $\sigma_{y}$ changes from 0 to -0.0108 and $\sigma_{x}=0$, the collector efficiency is increased by $1.3 \%$ because of increase in heat transfer due to wide spread of heat flux on the outer surface of the absorber tube as seen in Figure 7(a). When $\sigma_{x}=0$, the collector efficiency for $\sigma_{y}=0.0163$ is $14 \%$ lower than the collector efficiency when $\sigma_{y}=-0.0163$, even though the optical efficiency is the same for both the cases. This is mainly because of the pattern of distribution of heat flux on the absorber tube as seen in Figure 7(a).

Figure 14(a)-(d) shows the variation in collector efficiency for different inlet fluid temperature ranging from $\mathrm{T}_{\mathrm{in}}=323 \mathrm{~K}$ to $523 \mathrm{~K}$ for receiver position error $\sigma_{x}=0,0.0054,0.108$ and 0.163 where the value of $\sigma_{y}$ ranges from 0.0163 to 0.0163 . The collector efficiency decreases with an increase in inlet fluid temperature for all the receiver position errors considered in this study. In all the cases approximately $7 \%$ fall in the efficiency is observed when inlet temperature increases from 323 to $573 \mathrm{~K}$ due to decrease in the temperature difference between absorber tube wall temperature and HTF temperature. It is also observed that irrespective of $\sigma_{x}$ value, the difference between the collector 
efficiency for all $\sigma_{y}$ values remains same along the temperature axis. Therefore, it can be concluded that the effect of inlet temperature and receiver position error on collector efficiency are independent.

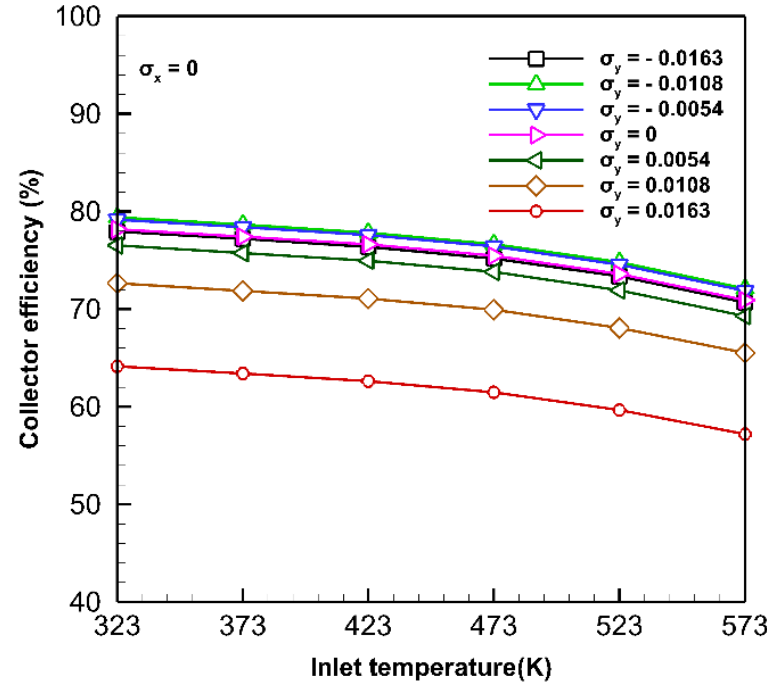

(a) $\sigma_{x}=0$

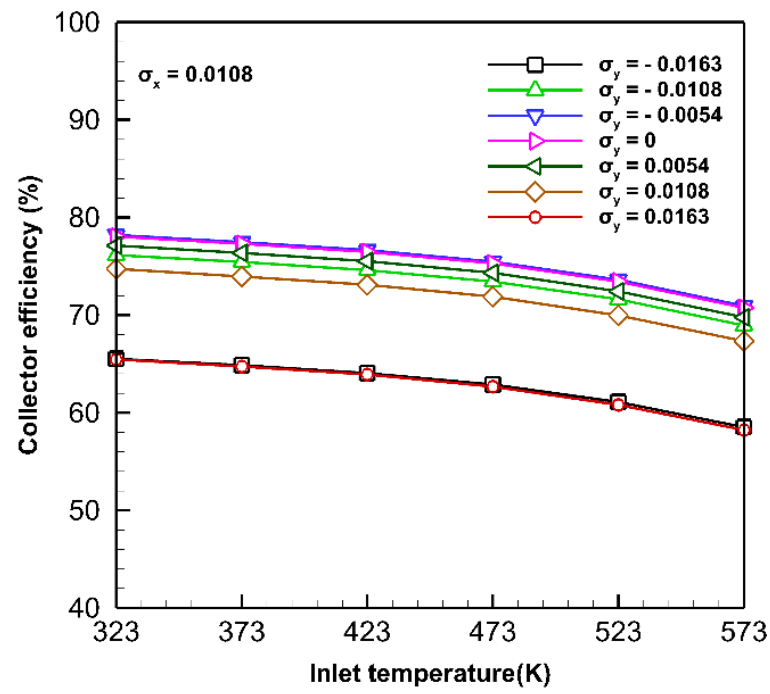

(c) $\sigma_{x}=0.0108$

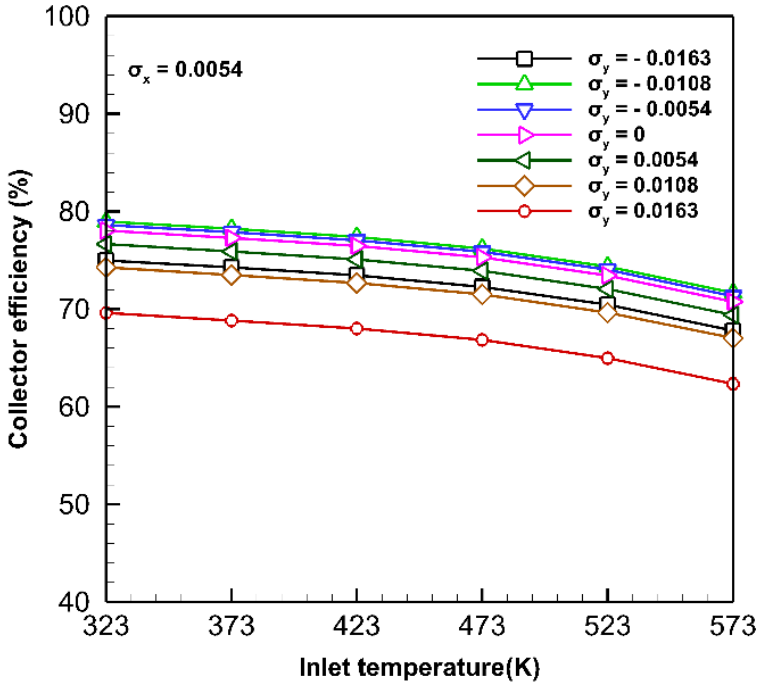

(b) $\sigma_{x}=0.0054$

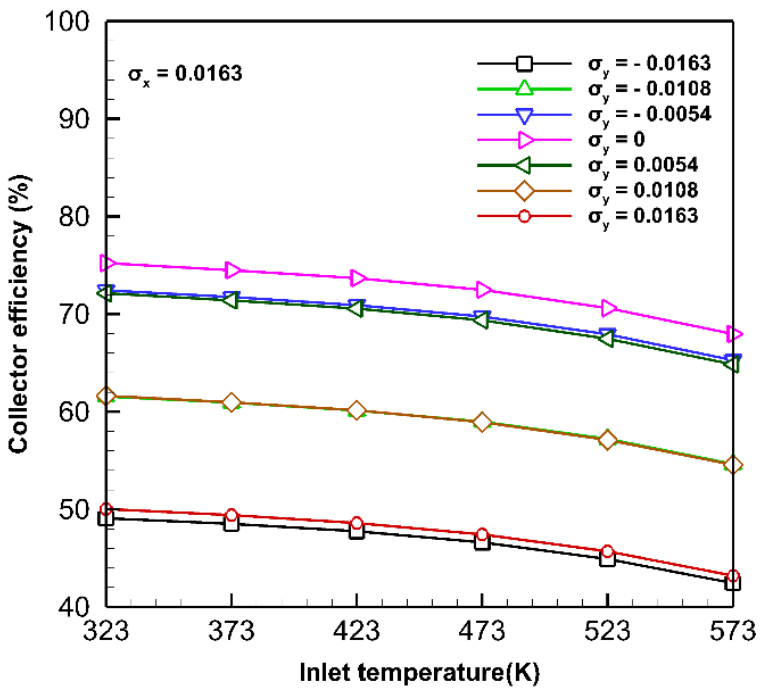

(d) $\sigma_{x}=0.0163$

Figure 14. Variation of collector efficiency with respect to inlet HTF temperature for $\sigma_{y}=-0.0163$ to 0.0163 and (a)

$$
\sigma_{x}=0 \text { (b) } \sigma_{x}=0.0054 \text { (c) } \sigma_{x}=0.0108 \text { (d) } \sigma_{x}=0.0163
$$

\section{CONCLUSIONS}

In this paper, the effect of the receiver position error on the optical and thermal performance of the parabolic trough solar collector has been studied and the results are presented. The simulations have been performed by coupling MCRT and FVM. Thus, it can be concluded that the receiver position error substantially influences the heat flux distribution on the absorber tube and significantly affects the thermal performance of the receiver.

The temperature distribution on the absorber tube in the circumferential direction follows the pattern of heat flux distribution, but it is flatter than the heat flux distribution. The maximum temperature and the non-uniformity of the temperature on the absorber tube increase with an increase in receiver position error in positive $y$-direction and these parameters decrease with increase in receiver position error in the negative y-direction. 
The variations in values of the optical efficiency are negligible for the equal amount of displacement of the receiver either in positive or in the negative y-direction from the ideal position. The optical efficiency drops by $2 \%$ when the receiver is offset from the focus by $1.63 \%$ of its focal length in the y-direction. It is found that the optical efficiency decreases by $4 \%$ when the receiver is displaced from the focus by $1.63 \%$ of its focal length in the $\mathrm{x}$ direction. A maximum drop of $32 \%$ in optical efficiency is observed when the receiver is eccentric from the focus by $1.63 \%$ of the focal length in both lateral directions.

The collector efficiency is found to be around $79 \%$ when the receiver is concentric with the focus of the trough. No significant variation in the collector efficiency is observed when the receiver is displaced by $1.63 \%$ of the focal length from the focus of the trough in the negative y-direction. The variation in the thermal efficiency is high (14\%) when the receiver is displaced by $1.63 \%$ of the focal length of the PTC from the focus in the positive y-direction. Therefore the displacement of the receiver in the y-direction (away from trough along the optical axis) is more critical in comparison to the $\mathrm{x}$-direction. The drop in the efficiency is more (28\%) when the receiver is displaced by $1.63 \%$ of the focal length of the PTC from the focus in both $\mathrm{x}$ and $\mathrm{y}$-directions. Therefore, it can be concluded that the receiver position error has a significant effect on collector efficiency.

\section{NOMENCLATURE}

\begin{tabular}{|c|c|}
\hline$c_{\mathrm{p}}$ & : specific heat $\left(\mathrm{J} \mathrm{kg}^{-1} \mathrm{~K}^{-1}\right)$ \\
\hline$d_{g i}$ & : glass tube inner diameter $(\mathrm{m})$ \\
\hline $\mathrm{d}_{\mathrm{go}}$ & : glass tube outer diameter $(\mathrm{m})$ \\
\hline $\mathrm{d}_{\mathrm{ri}}$ & : absorber tube inner diameter $(\mathrm{m})$ \\
\hline $\mathrm{d}_{\mathrm{ro}}$ & : absorber tube outer diameter $(\mathrm{m})$ \\
\hline$f$ & : focal length $(\mathrm{m})$ \\
\hline $\bar{f}$ & : average friction coefficient \\
\hline $\mathrm{h}$ & : heat transfer coefficient $\left(\mathrm{W} \mathrm{m} \mathrm{m}^{-2} \mathrm{~K}^{-1}\right)$ \\
\hline I & : direct normal irradiance $\left(\mathrm{W} \mathrm{m}^{-2}\right)$ \\
\hline $\mathrm{L}$ & : length of receiver tube $(\mathrm{m})$ \\
\hline$\dot{m}$ & : HTF mass flow rate $\left(\mathrm{kg} \mathrm{s}^{-1}\right)$ \\
\hline$\overline{N u}$ & : average Nusselt number \\
\hline q & : local heat flux on absorber tube $\left(\mathrm{W} \mathrm{m}^{-2}\right)$ \\
\hline $\mathrm{T}$ & : temperature $(\mathrm{K})$ \\
\hline $\mathrm{T}_{\mathrm{a}}$ & : ambient air temperature $(\mathrm{K})$ \\
\hline $\mathrm{T}_{\text {in }}$ & : inlet temperature of $\mathrm{HTF}(\mathrm{K})$ \\
\hline $\mathrm{T}_{\max }$ & : maximum temperature on absorber tube $(\mathrm{K})$ \\
\hline $\mathrm{T}_{\text {out }}$ & : outlet temperature of HTF $(\mathrm{K})$ \\
\hline $\mathrm{T}_{\text {ro }}$ & : absorber tube surface temperature $(\mathrm{K})$ \\
\hline $\mathrm{T}_{\text {sky }}$ & : external radiation temperature $(\mathrm{K})$ \\
\hline$\overline{\mathrm{T}}$ & : average temperature of HTF at a cross-section $(\mathrm{K})$ \\
\hline$\Delta \mathrm{T}$ & : difference between maximum and minimum temperature on absorber tube $(\mathrm{K})$ \\
\hline$\Delta \mathrm{x}$ & : displacement of receiver from focus in $\mathrm{x}$-direction $(\mathrm{m})$ \\
\hline$\Delta y$ & : displacement of receiver from focus in y-direction $(\mathrm{m})$ \\
\hline $\mathrm{V}_{\mathrm{w}}$ & : wind velocity $\left(\mathrm{m} \mathrm{s}^{-1}\right)$ \\
\hline$Q_{c}$ & : solar energy absorbed by HTF (W) \\
\hline $\mathrm{Q}_{\text {lost }}$ & : heat loss $(\mathrm{W})$ \\
\hline W & : aperture width (m) \\
\hline \multicolumn{2}{|c|}{ Greek symbols } \\
\hline$\alpha_{\mathrm{r}}$ & : absorber tube absorptivity \\
\hline$\varepsilon_{\mathrm{ro}}$ & : emissivity of absorber coating \\
\hline$\rho_{\mathrm{m}}$ & : mirror reflectivity \\
\hline
\end{tabular}


Journal of Thermal Engineering, Research Article, Vol. 7, No. 1, pp. 271-290, January, 2021

$\begin{array}{ll}\rho_{r} & : \text { absorber tube reflectivity } \\ \rho_{g} & : \text { glass tube reflectivity } \\ \sigma_{\text {dis }} & : \text { receiver position error distribution }(\mathrm{mrad}) \\ \sigma_{\text {mir }} & : \text { mirror specularity distribution }(\mathrm{mrad}) \\ \sigma_{\text {slo }} & : \text { slope error distribution }(\mathrm{mrad}) \\ \sigma_{\text {sun }} & : \text { sun's energy distribution }(\mathrm{mrad}) \\ \sigma_{\text {tot }} & : \text { total error distribution }(\mathrm{mrad}) \\ \sigma_{\text {tra }} & : \text { tracking error distribution }(\mathrm{mrad}) \\ \sigma_{\mathrm{x}} & : \text { receiver position error in x-direction } \\ \sigma_{\mathrm{y}} & : \text { receiver position error in y-direction } \\ \varphi_{\mathrm{r}} & : \text { rim angle (degrees) } \\ \tau_{\mathrm{g}} & : \text { glass tube transmissivity } \\ \tau_{m} & : \text { mirror transmissivity } \\ \eta_{\mathrm{c}} & : \text { collector efficiency } \\ \eta_{\mathrm{o}} & : \text { optical efficiency } \\ \text { Abbreviations } & \\ \text { CSP } & : \text { concentrated solar power } \\ \text { DNI } & : \text { direct normal irradiation } \\ \text { FVM } & : \text { finite volume method } \\ \text { HTF } & : \text { heat transfer fluid } \\ \text { LCR } & : \text { local concentration ratio } \\ \text { MCRT } & : \text { Monte Carlo ray tracing } \\ \text { PTC } & : \text { parabolic trough collector }\end{array}$

\section{REFERENCES}

[1] Taner T, Dalkilic AS. A feasibility study of solar energy-techno economic analysis from Aksaray city, Turkey. J Therm Eng 2019;5:25-30. doi:10.18186/thermal.505498

[2] Kerme ED, Orfi J. Exergy-based thermodynamic analysis of solar driven organic Rankine cycle. J Therm Eng 2015;1:192-202. doi:10.18186/jte.25809.

[3] Loni R, Kasaeian AB, Asli-Ardeh EA, Ghobadian B, Najafi G. Comparison study of air and thermal oil application in a solar cavity receiver. J Therm Eng 2019;5:221-9. doi:10.18186/thermal.654628.

[4] Ghomrassi A, Mhiri H, Bournot P. Numerical study and optimization of parabolic trough solar collector receiver tube. J Sol Energy Eng Trans ASME 2015;137:051003. doi:10.1115/1.4030849.

[5] Treadwell GW. Design considerations for parabolic-cylindrical solar collectors, Albuquerque: SAND760082.1976.

[6] Bendt P, Rabl A, Gaul HW, Reed KA. Optical analysis and optimization of line focus solar collectors. Seri/Tr-34-09 1979.

[7] Ratzel AC. Receiver Assembly Design Studies for 2-m 90 ParabolicCylindrical Solar Collectors, in Sandia Laboratories. 1979.

[8] Rabl A. Active Solar Collectors and Their Applications. New York: Oxford University Press; 1985.

[9] Pettit RB, Vittitoe CN, Biggs F. Simplified Calculational Procedure for Determining the Amount of Intercepted Sunlight in an Imaging Solar Concentrator. J Sol Energy Eng Trans ASME 1983;105:101-7. doi:10.1115/1.3266335.

[10] Forristall R. Heat Transfer Analysis and Modeling of a Parabolic Trough Solar Receiver Implemented in Engineering Equation Solver. United States: 2003. NRELTechnical Report. p. 1-145. doi:NREL/TP-55034169.

[11] Li M, Wang LL. Investigation of evacuated tube heated by solar trough concentrating system. Energy Convers Manag 2006;47:3591-601. doi:10.1016/j.enconman.2006.03.003.

[12] Yettou F, Gama A, Panwar NL, Azoui B, Malek A. Receiver temperature maps of parabolic collector used for solar food cooking application in Algeria. J Therm Eng 2018;4:1656-67. doi:10.18186/journal-ofthermal-engineering.364866. 
Journal of Thermal Engineering, Research Article, Vol. 7, No. 1, pp. 271-290, January, 2021

[13] Loni R, Kasaeian A, Asli-Ardeh EA, Ghobadian B, Najafi G. Thermal evaluation of cavity receiver using water/Pg as the solar working fluid. J Therm Eng 2019;5:446-55. doi:10.18186/thermal.624341.

[14] Price H, Lu" pfert E, Kearney D, Zarza E, Cohen G, Gee R, et al. Advances in Parabolic Trough Solar Power Technology . J Sol Energy Eng 2002;124:109-25. doi:10.1115/1.1467922.

[15] Padilla RV, Demirkaya G, Goswami DY, Stefanakos E, Rahman MM. Heat transfer analysis of parabolic trough solar receiver. Appl Energy 2011;88:5097-110. doi:10.1016/J.APENERGY.2011.07.012.

[16] Mwesigye A, Huan Z, Bello-Ochende T, Meyer JP. Influence of optical errors on the thermal and thermodynamic performance of a solar parabolic trough receiver. Sol Energy 2016;135:703-18. doi:10.1016/j.solener.2016.06.045.

[17] Zhu G. Study of the optical impact of receiver position error on parabolic trough collectors. J Sol Energy Eng Trans ASME 2013;135:1-5. doi:10.1115/1.4024247.

[18] Güven HM, Bannerot RB. Derivation of universal error parameters for comprehensive optical analysis of parabolic troughs. J Sol Energy Eng Trans ASME 1986;108:275-81. doi:10.1115/1.3268106.

[19] Thomas A, Guven HM. Effect of optical errors on flux distribution around the absorber tube of a parabolic trough concentrator. Energy Convers Manag 1994;35:575-82. doi:10.1016/0196-8904(94)90040-X.

[20] Lüpfert E, Pottler K, Ulmer S, Riffelmann KJ, Neumann A, Schiricke B. Parabolic trough optical performance analysis techniques. J Sol Energy Eng Trans ASME 2007;129:147-52. doi:10.1115/1.2710249.

[21] Maccari A, Montecchi M. An optical profilometer for the characterisation of parabolic trough solar concentrators. Sol Energy 2007;81:185-94. doi:10.1016/j.solener.2006.04.004.

[22] García-Cortés S, Bello-García A, Ordóñez C. Estimating intercept factor of a parabolic solar trough collector with new supporting structure using off-the-shelf photogrammetric equipment. Appl Energy 2012;92:81521. doi:10.1016/j.apenergy.2011.08.032.

[23] Ulmer S, Heinz B, Pottler K, Lüpfert E. Slope error measurements of parabolic troughs using the reflected image of the absorber tube. J Sol Energy Eng Trans ASME 2009;131:0110141-5. doi:10.1115/1.3035811.

[24] Skouri S, Ben Salah M, Bouadila S, Balghouthi M, Ben Nasrallah S. Optical, geometric and thermal study for solar parabolic concentrator efficiency improvement under Tunisia environment: A case study. Energy Convers Manag 2013;75:366-73. doi:10.1016/j.enconman.2013.06.022.

[25] Balghouthi M, Ali ABH, Trabelsi SE, Guizani A. Optical and thermal evaluations of a medium temperature parabolic trough solar collector used in a cooling installation. Energy Convers Manag 2014;86:1134-46. doi:10.1016/j.enconman.2014.06.095.

[26] Gaul H, Rabl A. Incidence-angle modifier and average optical efficiency of parabolic trough collectors. J Sol Energy Eng Trans ASME 1980;102:16-21. doi:10.1115/1.3266115.

[27] Zhao D, Xu E, Wang Z, Yu Q, Xu L, Zhu L. Influences of installation and tracking errors on the optical performance of a solar parabolic trough collector. Renew Energy 2016;94:197-212. doi:10.1016/j.renene.2016.03.036.

[28] Ratzel AC. Annular Solar Receiver Thermal Characteristics, in Sandia National Laboratories. 1980.

[29] Treadwell GW, Grandjean NR. Systematic rotation and receiver location error effects on parabolic trough annual performance. J Sol Energy Eng Trans ASME 1982;104:345-8. doi:10.1115/1.3266328.

[30] Binotti M, Zhu G, Gray A, Manzolini G, Silva P. Geometric analysis of three-dimensional effects of parabolic trough collectors. Sol Energy 2013;88:88-96. doi:10.1016/j.solener.2012.10.025.

[31] Jeter SM. Calculation of the concentrated flux density distribution in parabolic trough collectors by a semifinite formulation. Sol Energy 1986;37:335-45. doi:10.1016/0038-092X(86)90130-1.

[32] Jeter SM. Analytical determination of the optical performance of practical parabolic trough collectors from design data. Sol Energy 1987;39:11-21. doi:10.1016/S0038-092X(87)80047-6.

[33] Khanna S, Sharma V. Explicit Analytical Expression for Solar Flux Distribution on an Undeflected Absorber Tube of Parabolic Trough Concentrator Considering Sun-Shape and Optical Errors. J Sol Energy Eng Trans ASME 2016;138. doi:10.1115/1.4032122.

[34] Delatorre J, Baud G, Bézian JJ, Blanco S, Caliot C, Cornet JF, et al. Monte Carlo advances and concentrated solar applications. Sol Energy 2014;103:653-81. doi:10.1016/j.solener.2013.02.035.

[35] Donga RK, Kumar S. Parabolic trough collector with rhombus tube absorber for higher concentration ratio. Energy Sources, Part A Recover Util Environ Eff 2018;40:2620-31. doi:10.1080/15567036.2018.1505981.

[36] Cheng ZD, He YL, Xiao J, Tao YB, Xu RJ. Three-dimensional numerical study of heat transfer characteristics in the receiver tube of parabolic trough solar collector. Int Commun Heat Mass Transf 2010;37:782-7. doi:10.1016/j.icheatmasstransfer.2010.05.002. 
Journal of Thermal Engineering, Research Article, Vol. 7, No. 1, pp. 271-290, January, 2021

[37] He YL, Xiao J, Cheng ZD, Tao YB. A MCRT and FVM coupled simulation method for energy conversion process in parabolic trough solar collector. Renew Energy 2011;36:976-85. doi:10.1016/j.renene.2010.07.017.

[38] Cheng ZD, He YL, Cui FQ, Xu RJ, Tao YB. Numerical simulation of a parabolic trough solar collector with nonuniform solar flux conditions by coupling FVM and MCRT method. Sol Energy 2012;86:1770-84. doi:10.1016/j.solener.2012.02.039.

[39] Sheikholeslami M. Numerical approach for MHD Al[Formula presented]O[Formula presented]-water nanofluid transportation inside a permeable medium using innovative computer method. Comput Methods Appl Mech Eng 2019;344:306-18. doi:10.1016/j.cma.2018.09.042.

[40] Sheikholeslami M, Haq R ul, Shafee A, Li Z. Heat transfer behavior of nanoparticle enhanced PCM solidification through an enclosure with V shaped fins. Int J Heat Mass Transf 2019;130:1322-42. doi:10.1016/j.ijheatmasstransfer.2018.11.020.

[41] Sheikholeslami M. New computational approach for exergy and entropy analysis of nanofluid under the impact of Lorentz force through a porous media. Comput Methods Appl Mech Eng 2019;344:319-33. doi:10.1016/j.cma.2018.09.044.

[42] Cheng ZD, He YL, Cui FQ. Numerical study of heat transfer enhancement by unilateral longitudinal vortex generators inside parabolic trough solar receivers. Int J Heat Mass Transf 2012;55:5631-41. doi:10.1016/j.ijheatmasstransfer.2012.05.057.

[43] Dudley VE, Kolb GJ, Mahoney AR, Mancini TR, Matthews CW, Sloan M, et al. Test results: SEGS LS-2 solar collector n.d. 1994. doi:10.2172/70756.

[44] Roesle M, Coskun V, Steinfeld A. Numerical analysis of heat loss from a parabolic trough absorber tube with active vacuum system. J Sol Energy Eng Trans ASME 2011;133. doi:10.1115/1.4004276.

[45] Li ZY, Huang Z, Tao WQ. Three-dimensional numerical study on fully-developed mixed laminar convection in parabolic trough solar receiver tube. Energy 2016;113:1288-303. doi:10.1016/j.energy.2016.07.148.

[46] Mwesigye A, Bello-Ochende T, Meyer JP. Numerical investigation of entropy generation in a parabolic trough receiver at different concentration ratios. Energy 2013;53:114-27. doi:10.1016/j.energy.2013.03.006.

[47] Wu Z, Li S, Yuan G, Lei D, Wang Z. Three-dimensional numerical study of heat transfer characteristics of parabolic trough receiver. Appl Energy 2014;113:902-11. doi:10.1016/j.apenergy.2013.07.050.

[48] Wirz M, Roesle M, Steinfeld A. Three-dimensional optical and thermal numerical model of solar tubular receivers in parabolic trough concentrators. J Sol Energy Eng Trans ASME 2012;134. doi:10.1115/1.4007494.

[49] Neumann A, Witzke A, Jones SA, Schmitt G. Representative terrestrial solar brightness profiles. J Sol Energy Eng Trans ASME 2002;124:198-204. doi:10.1115/1.1464880.

[50] Lazarus G, Roy S, Kunhappan D, Cephas E, Wongwises S. Heat transfer performance of silver/water nanofluid in a solar flat-plate collector. J Therm Eng 2015;1:104-12. doi:10.18186/jte.29475.

[51] Menni Y, Azzi A, Zidani C. Cfd simulation of thermo-aeraulic fields in a channel with multiple baffle plates. J Therm Eng 2018;4:2481-95. doi:10.18186/thermal.465696.

[52] Yildirim C, Tümen Özdil NF. Theoretical investigation of a solar air heater roughened by ribs and grooves. J Therm Eng 2018;4:1702-12. doi:10.18186/journal-of-thermal-engineering.365713.

[53] Dutta J, Kundu B. Thermal analysis on variable thickness absorber plate fin in flat-plate solar collectors using differential transform method. J Therm Eng 2020;6:158-69. doi:10.18186/THERMAL.672169.

[54] Mullick SC, Nanda SK. An improved technique for computing the heat loss factor of a tubular absorber. Sol Energy 1989;42:1-7. doi:https://doi.org/10.1016/0038-092X(89)90124-2. 